\title{
molecules
}

ISSN 1420-3049

www.mdpi.com/journal/molecules

Article

\section{Synthesis and Biological Evaluation of Novel Urea- and Guanidine-Based Derivatives for the Treatment of Obesity-Related Hepatic Steatosis}

\author{
Xiaolin Liang ${ }^{\dagger}$, Heying Pei ${ }^{\dagger}$, Liang Ma, Yan Ran, Jinying Chen, Guangcheng Wang and \\ Lijuan Chen *
}

State Key Laboratory of Biotherapy, West China Hospital, West China Medical School, Sichuan University, Keyuan Road 4, Gaopeng Street, Chengdu 610041, China;

E-Mails: liang_11@hsit.edu.cn (X.L.); pei_2014@hsit.edu.cn (H.P.); liang_m@scu.edu.cn (L.M.); ran_2014@hsit.edu.cn (Y.R.); chen_2011@hsit.edu.cn (J.C.); wang_gc12@hsit.edu.cn (G.W.)

$\dagger$ These authors contributed equally to this work.

* Author to whom correspondence should be addressed; E-Mail: chenlijuan125@163.com;

Tel.: +86-28-8516-4063; Fax: +86-28-8516-4060.

Received: 3 March 2014; in revised form: 14 April 2014 / Accepted: 15 April 2014 /

Published: 15 May 2014

\begin{abstract}
Leptin, the product of the obese gene, is an adipocyte-secreted protein hormone playing a key role in the progression of obesity and hepatic steatosis. In this study, 28 novel (thio)urea and guanidine-based analogues have been synthesized and N-(1-(4-(3(2-chloroethyl)ureido)benzyl)piperidin-4-yl)-3-(trifluoromethyl) benzamide (7i) was found to be a potent regulator of leptin expression in 3T3-L1 adipocytes. Treatment with $7 \mathbf{i}$ at a dose of $50 \mathrm{mg} / \mathrm{kg} /$ day for 35 days reduced the body weight and liver weight of diet-induced obesity mice by $13.5 \%$ and $18.4 \%$, respectively, while also improving the serum levels of triglyceride, total cholesterol, leptin, adiponectin, LDL-c, HDL-c. Hematoxylin-eosin (H\&E) and Oil Red O staining also confirmed that $7 \mathbf{i}$ ameliorated fat deposition in liver tissue and restricted the size of adipocytes in obesity-related fatty liver disease.
\end{abstract}

Keywords: leptin; hepatic steatosis; urea and guanidine-based; diet-induced obesity 


\section{Introduction}

Obesity, with an increasing prevalence around the world, has been cited by the World Health Organization as one of the greatest public health challenges [1,2]. It is considered a serious health problem because of the high incidence of other metabolic syndromes such as type 2 diabetes, cardiovascular disease, and osteoarthritis seen in obese individuals $[3,4]$. In gastroenterology, obesityrelated complications are also frequent, and the consequences of obesity for the liver have attracted more attention because of its crucial role in metabolism [5].

Hepatic steatosis, which manifests at a high rate in overweight or obese individuals as fat infiltration and deposition, is a precursor of advanced non-alcoholic fatty liver diseases (NAFLDs) [6,7]. Currently, $34 \%$ of the general population and over $75 \%$ of obese individuals are estimated to have fatty liver diseases [8-10]. The high association between obesity and fatty liver disease may result from the serum concentration changes of several important adipokines and one such adipokine is the $16 \mathrm{kDa}$ protein hormone leptin [11]. Leptin, a cytokine secreted by adipose tissue, plays a central role in the regulation of energy balance via the activation of leptin receptors, particularly within the central nervous system [12]. It has been demonstrated that the serum leptin concentration in obese subjects is higher than in non-obese subjects, with a significant correlation between body weight and circulating serum leptin levels $[13,14]$.

Although the actual mechanisms leading to hepatic steatosis in obese individuals remain unclear, insulin resistance (IR) and abnormal lipid metabolism are generally accepted as the essential risk factors of obesity-related fatty liver disease [15]. In fact, elevated leptin levels in obesity inhibit insulin signaling and enhance the IR effect, which leads to an increase in intracellular fatty acids and deposition of triglycerides (TG) in the hepatocytes [16-20]. Recent studies also showed that obesity-induced leptin functions directly in promoting the progression of non-alcoholic steatohepatitis [21-23]. These compelling evidences suggested that leptin could be a potential therapeutic target of obesity-related fatty liver disease.

As insulin sensitizers, metformin and rosiglitazone have been proved effective in the clinic to reduce the serum leptin levels and improve the situation of hepatic steatosis [24-26]. However, it was generally accepted that the use of TZDs would cause hepatotoxicity and increase the risk of heart failure [27,28], which has provided the impetus to develop a series of novel compounds integrating the structural characteristics of metformin and rosiglitazone and investigate their pharmaceutical functions against obesity-related fatty liver disease. As shown in Figure 1, the long chain motif of rosiglitazone has been kept with the changed 4-formamide- $N$-methylpiperidine or 4-hydroxy- $N$-ethanonepiperidine bridges between two benzene rings, and then guanidine was introduced to the para-position of ring $\mathrm{B}$ where a substituted thiazolidine was originally. Furthermore, as guanidine's isosteric urea core has also shown capacity in decreasing liver TG [29], this encouraged us to try to replace guanidine with (thio)urea moieties. As a result compound $7 \mathbf{i}$ was discovered to be a good leptin regulator and to improve hepatic steatosis symptoms in DIO mice. 
Figure1. Rationale for the design of compounds $7 \mathbf{a}-\mathbf{l}, \mathbf{8 a}-\mathbf{c}, \mathbf{1 4 a}-\mathbf{d}, \mathbf{1 7} \mathbf{a}-\mathbf{i}$.

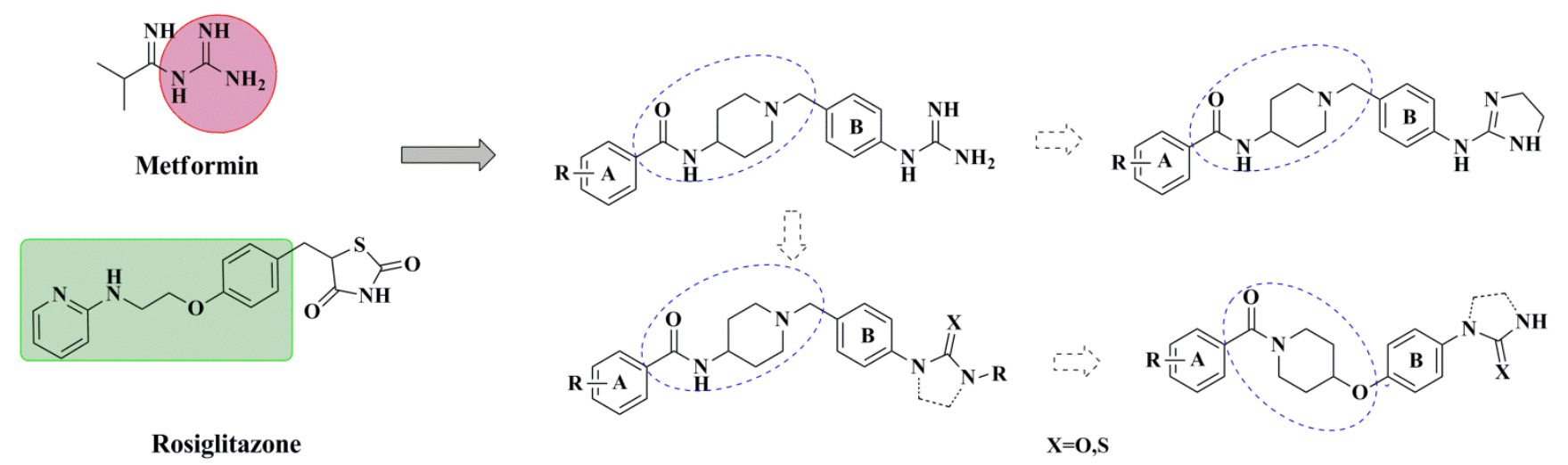

\section{Results and Discussion}

\subsection{Chemistry}

These urea derivatives 7 and thiourea derivatives 8 were prepared using the protocol outlined in Scheme 1. Compound 3 was synthesized via the reaction of 4-nitrobenzyl bromide and tert-butyl piperidin-4-ylcarbamate in the presence of $\mathrm{K}_{2} \mathrm{CO}_{3}$ as base and acetone as solvent. Then, the tert-butyloxycarbonyl (Boc) protection was removed in TFA at $0{ }^{\circ} \mathrm{C}$ and treatment of the resulting trifluoroacetate with various substituted benzoic acids in the presence of EDCI and DMAP yielded compounds 5. The chemical reduction was conducted in anhydrous EtOH under reflux in the presence of $\mathrm{SnCl}_{2}$ to give the corresponding amines $\mathbf{6}$. Finally, treatment of various amines $\mathbf{6}$ with the corresponding iso(thio)cyanates in DCM at $0{ }^{\circ} \mathrm{C}$ afforded the desired (thio)urea derivatives 7 and 8 (Scheme 1 and Table 1).

Scheme 1. Synthesis of compounds $7 \mathbf{a}-\mathbf{l}$ and $\mathbf{8 a}-\mathbf{c}$.

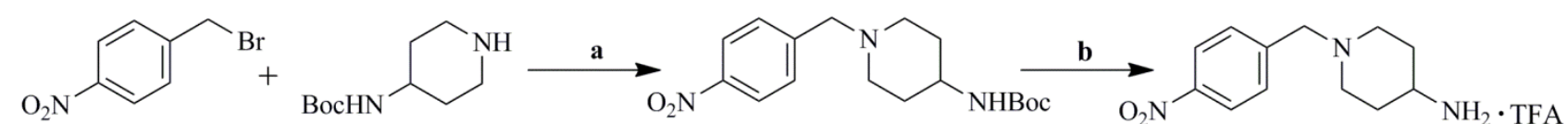

1

2

3
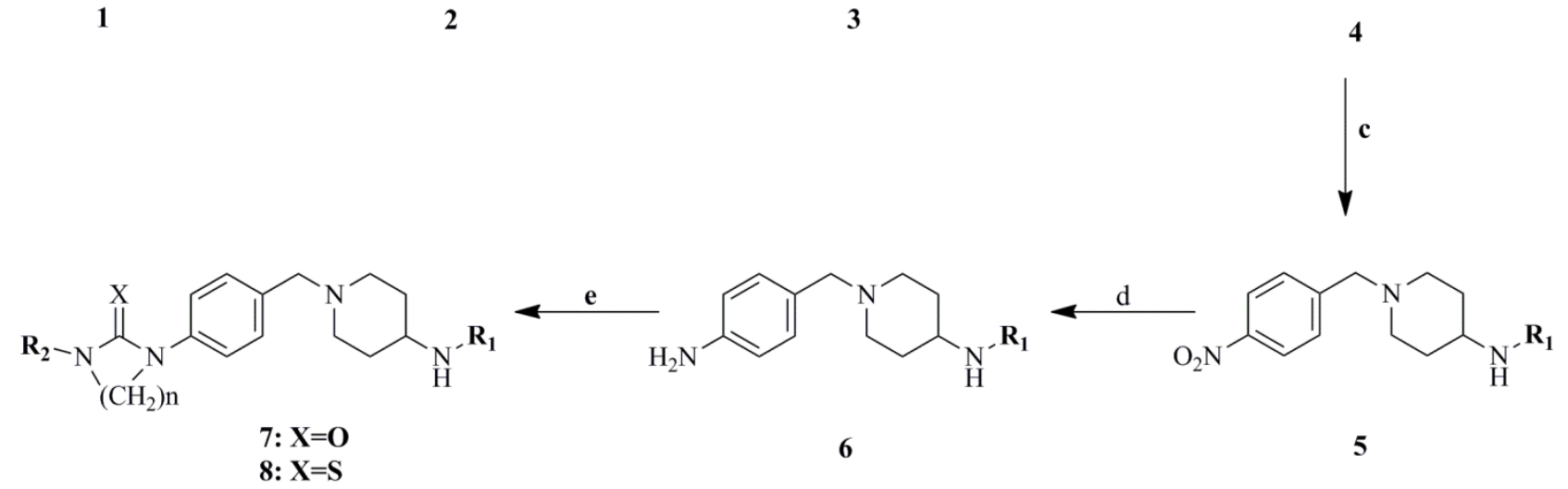

Reagents and conditions: (a) $\mathrm{K}_{2} \mathrm{CO}_{3}$, acetone, $70{ }^{\circ} \mathrm{C}, 4 \mathrm{~h}, 95.2 \%$; (b) TFA, DCM, $0{ }^{\circ} \mathrm{C}$ to room temperature, 3 h, 96.8\%; (c) R $\mathrm{COOH}$, EDCI, DMAP, DCM, room temperature, overnight, 65\%-75\%; (d) $\mathrm{SnCl}_{2}, \mathrm{EtOH}$, $2 \mathrm{~h}, 80{ }^{\circ} \mathrm{C}, 45 \%-75 \%$; (e) method A for 7a-7i, 8: substituted iso(thio)cyanate, DCM, $0{ }^{\circ} \mathrm{C}$ to room temperature, $30 \%-70 \%$; method $\mathrm{B}$ for $\mathbf{7} \mathbf{j}-\mathbf{7 l}$ : $\mathrm{NaH}$, correspond 7 , THF, $0{ }^{\circ} \mathrm{C}$ to room temperature, $30 \%-70 \%$. 
Table 1. Structural and Inhibition Effects of Leptin Expression on 3T3-L1 of 7a-1, 8a-c.<smiles>[R]NC1CCN(Cc2ccc(N(C)C([Y])N(C)C)cc2)CC1</smiles>

$7 \mathbf{a}-\mathbf{l}: \mathbf{X}=\mathbf{O}$

8a-c: $X=S$

\begin{tabular}{|c|c|c|c|c|}
\hline No. & $\mathbf{n}$ & $\mathbf{R}_{1}$ & $\mathbf{R}_{\mathbf{2}}$ & Inhibition of Leptin expression in 3T3-L1 (\%) \\
\hline $7 \mathbf{a}$ & 0 & & & 84.3 \\
\hline $7 b$ & 0 & & & 67.4 \\
\hline $7 c$ & 0 & & & 67.5 \\
\hline $7 d$ & 0 & & & 54.3 \\
\hline $7 e$ & 0 & & & 73.9 \\
\hline $7 f$ & 0 & & & 68.1 \\
\hline $7 \mathrm{~g}$ & 0 & & & 77.1 \\
\hline $7 \mathrm{~h}$ & 0 & & & 74.5 \\
\hline $7 \mathbf{i}$ & 0 & & & 89.0 \\
\hline $7 \mathbf{j}$ & 2 & & $\mathrm{H}$ & 54.1 \\
\hline $7 \mathbf{k}$ & 2 & & $\mathrm{H}$ & 69.2 \\
\hline 71 & 2 & & $\mathrm{H}$ & 78.4 \\
\hline $8 \mathbf{a}$ & 0 & & & 61.4 \\
\hline
\end{tabular}


Table 1. Cont.

\begin{tabular}{|c|c|c|c|c|}
\hline No. & $\mathbf{n}$ & $\mathbf{R}_{1}$ & $\mathbf{R}_{\mathbf{2}}$ & Inhibition of Leptin expression in 3T3-L1 (\%) ${ }^{a}$ \\
\hline $8 b$ & 0 & & & 48.1 \\
\hline $8 c$ & 0 & & & 45.0 \\
\hline Metformin & & & & 39.3 \\
\hline
\end{tabular}

${ }^{a}$ the result of inhibition effect were results were recorded from three independent experiments.

Intermediates 6 were treated with $N, N^{\prime}$-di(tert-butoxycarbonyl)thiourea in the presence of triethylamine (TEA) and mercury (II) chloride to give 16, as described in Scheme 2. Deprotection of 16 yielded the desired guanidine analogues 17 (Scheme 2 and Table 2).

Scheme 2. Synthesis of compounds $17 \mathbf{a}-\mathbf{i}$.

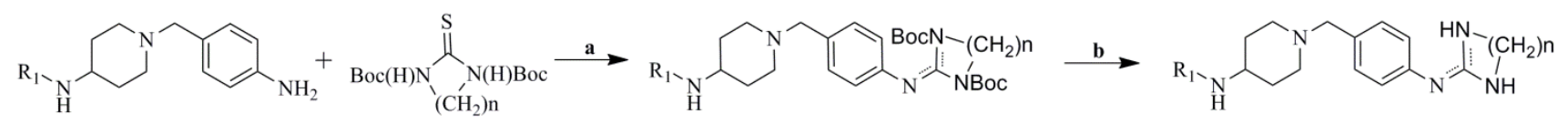

6

15

16

17

Reagents and conditions: (a) $N, N^{\prime}$-Bis-tert-butoxycarbonylthiourea(or imidazolidinethione), $\mathrm{HgCl}_{2}$, TEA, EtOH, DCM, $0{ }^{\circ} \mathrm{C}$ to room temperature, overnight, $30 \%-50 \%$; (b) TFA, DCM, $0{ }^{\circ} \mathrm{C}$ to room temperature, $3 \mathrm{~h}, 20 \%-40 \%$.

Table 2. Structural and Inhibition Effects of Leptin Expression on 3T3-L1 of 17a-i.<smiles>[R]NC1CCN(Cc2ccc(N=C(NCC)NCC)cc2)CC1</smiles>

$17 \mathbf{a}-\mathbf{i}$

\begin{tabular}{|c|c|c|c|}
\hline No. & n & $\mathbf{R}_{1}$ & Inhibition of Leptin expression in 3T3-L1(\%) \\
\hline $17 \mathbf{a}$ & $\mathbf{0}$ & & 53.0 \\
\hline $17 b$ & $\mathbf{0}$ & & 42.5 \\
\hline $17 \mathrm{c}$ & $\mathbf{0}$ & & 42.3 \\
\hline 17d & $\mathbf{0}$ & & 22.8 \\
\hline $17 \mathrm{e}$ & $\mathbf{0}$ & & 15.1 \\
\hline
\end{tabular}


Table 2. Cont.

\begin{tabular}{|c|c|c|c|}
\hline No. & $\mathbf{n}$ & $\mathbf{R}_{1}$ & Inhibition of Leptin expression in 3T3-L1(\%) \\
\hline $17 f$ & $\mathbf{0}$ & & 27.5 \\
\hline $17 \mathrm{~g}$ & $\mathbf{0}$ & & 34.5 \\
\hline $17 \mathrm{~h}$ & 2 & & 33.6 \\
\hline $17 \mathbf{i}$ & 2 & & 18.7 \\
\hline Metformin & & & 39.3 \\
\hline
\end{tabular}

${ }^{a}$ the result of inhibition effect were results were recorded from three independent experiments.

Then, to explore the structure activity relationship (SAR) further, 4-piperidinol-substituted urea analogues have been synthesized as described in Scheme 3.

Scheme 3. Synthesis of compounds $17 \mathbf{a}-\mathbf{i}$.<smiles>CC(C)(C)C1CCN(C(=O)c2ccccc2)CC1</smiles>

9<smiles>O=[N+]([O-])c1ccc(O)cc1</smiles>

10

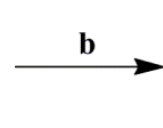<smiles>O=[N+]([O-])c1ccc(OC2CCNCC2)cc1</smiles>

11

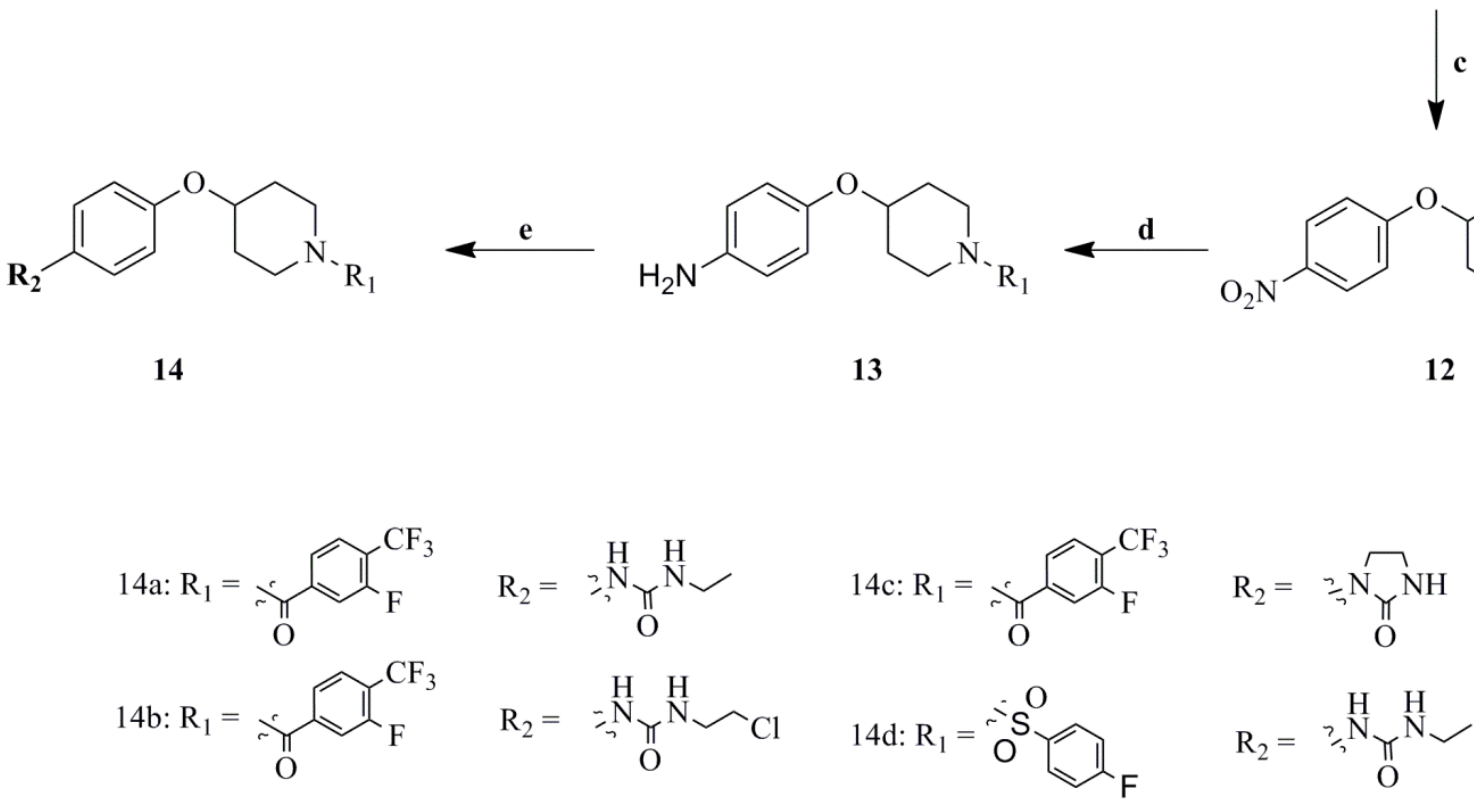

Reagents and conditions: (a) TsCl, pyridine, $0{ }^{\circ} \mathrm{C}$ to room temperature, overnight, $95.2 \%$; (b) (i) $\mathrm{K}_{2} \mathrm{CO}_{3}$, DMF, $100{ }^{\circ} \mathrm{C}, 89.7 \%, 8 \mathrm{~h}$; (ii) TFA, DCM, $0{ }^{\circ} \mathrm{C}$ to room temperature, $3 \mathrm{~h}, 97.1 \%$; (c) $\mathrm{R}_{1} \mathrm{COOH}$, EDCI, DMAP, DCM, room temperature, overnight, $65 \%-75 \%$; (d) $\mathrm{Pd} / \mathrm{C}, \mathrm{HCOONH}_{4}, \mathrm{MeOH}, 2 \mathrm{~h}, 70^{\circ} \mathrm{C}, 45 \%-75 \%$; (e) method A for $\mathbf{1 4 a}, \mathbf{1 4 b}, \mathbf{1 4 d}$ : substituted iso(thio)cyanate, DCM, $0{ }^{\circ} \mathrm{C}$ to room temperature, $30 \%-70 \%$; method B for $\mathbf{1 4 c}$ : $\mathrm{NaH}, \mathbf{1 4 b}$, THF, $0{ }^{\circ} \mathrm{C}$ to room temperature, $30 \%-70 \%$. 
The preparation of 4-piperidinol-substituted urea analogues was carried out via treatment of tert-butyl 4-hydroxypiperidine-1-carboxylate with $p$-toluenesulfonyl chloride $(\mathrm{TsCl})$ at $0{ }^{\circ} \mathrm{C}$ in pyridine as solvent giving 9 in a good yield. The reaction of 9 and 4-nitrophenol using $\mathrm{K}_{2} \mathrm{CO}_{3}$ as a base, and subsequent deprotection of the Boc group yielded 11. The pivotal amines 13 were obtained via the $\mathrm{Pd} / \mathrm{C}$ reduction of $\mathbf{1 2}$ in $\mathrm{MeOH}$ at reflux. Compounds 14 were obtained by the same methods as 7 and $\mathbf{8}$ (Scheme 3 and Table 3).

Table 3. Structural and Inhibition Effects of Leptin Expression on 3T3-L1 of 14a-c.<smiles>[R2]c1ccc(OC2CCN([R])CC2)cc1</smiles>

$14 \mathbf{a}-\mathbf{c}$

\begin{tabular}{|c|c|c|c|}
\hline No. & $\mathbf{R}_{1}$ & $\mathbf{R}_{\mathbf{2}}$ & Inhibition of Leptin expression in 3T3-L1 (\%) ${ }^{a}$ \\
\hline $14 a$ & & & 42.5 \\
\hline $14 b$ & & & 45.0 \\
\hline 14c & & & 50.3 \\
\hline 14d & & & 24.8 \\
\hline Metformin & & & 39.3 \\
\hline
\end{tabular}

${ }^{a}$ The result of inhibition effect were results were recorded from three independent experiments.

\subsection{Expression of Leptin in 3T3-L1 Adipocytes}

During the in vitro screening, these compounds containing (thio)urea and guanidine were evaluated at $10 \mu \mathrm{M}$ for their activity in decreasing leptin expression in 3T3-L1 adipocytes. Metformin was used as positive control and all tests were performed three times using each agent (Tables 1-3).

As shown in Table 1, leptin expressions was all inhibited after treatment with (thio)urea analogues at $10 \mu \mathrm{M}$. Compound $7 \mathbf{i}$ exhibited the most significant activity and reduced the leptin level by $89.0 \%$ compared to metformin which decreased leptin by $39.3 \%$. Further inspection of their structural features showed that the potencies of the thiourea analogues 8 were in general inferior to those of the urea analogues 7. As for the compounds 7, the introduction of chloroethyl as a tail group in the $\mathrm{R}_{2}$ position ( $7 \mathbf{g}-\mathbf{i})$ led to better efficacy than ethyl or allyl groups $(7 \mathbf{a}-\mathbf{f})$. Cyclizations of $7 \mathrm{~g}-\mathrm{i}$ were also carried out, which only caused the loss rather than an increase of bioactivity $(7 \mathbf{j}-\mathbf{k})$.

In Table 2, the analogues substituting (thio)urea for guanidine all displayed weak capability in down-regulating leptin level in 3T3-L1 adipocytes, which further demonstrated that the urea moiety was very important for the pharmaceutical activity. Moreover, two bridges, more specifically, 4aminopiperidine and 4-hydroxypiperidine (14a-d, Table 3 ) were compared and the 4-aminopiperidine linker turned out to be better than 4-hydroxypiperidine for the bioactivity. 
Finally, regarding the role of substituent groups in the phenyl ring $\mathrm{R}_{1}$ position, it seemed that the compounds with a trifluoromethyl group always displayed better activities than those with other substituents, which might because of the special effect contributed by this group on compounds' physicochemical and conformational properties [30].

\subsection{Activity in Diet-Induced Obesity (DIO) Mice}

Given the excellent in vitro leptin level lowering capability of $\mathbf{7 i}$, it was chosen to evaluate the in vivo activity in a diet-induced obesity (DIO) model. DIO is associated with hyperleptinemia and hepatic steatosis in $\mathrm{C} 57 \mathrm{Bl} / 6 \mathrm{~J}$ mice [31,32]. After oral administration with $7 \mathbf{i}$ once daily at $50 \mathrm{mg} / \mathrm{kg}$ for five weeks, the average body weight and liver weight was reduced by $13.5 \%$ and $18.4 \%$, respectively, despite the consistent food intake compared to the untreated high-fat diet (HFD) group (Figure 2). Subsequently, corresponding with the screening result in 3T3-L1 adipocytes, 7i notably reduced the serum level of leptin by $34.6 \%$, as well as TG, total cholesterol (TC), LDL-c and HDL-c which were respectively reduced by $17.3 \%, 25.0 \%, 57.7 \%$, and $20.9 \%$. Adiponectin, which counteracted the effect of leptin in aggravating IR, is considered ia protector in hepatic steatosis and NASH [33-35]. The in vivo test showed that the serum level of adiponectin was remarkably elevated by $93.0 \%$ after treatment with 7i. Nevertheless the changes of aspartate aminotransferase (AST), alanine transaminase (ALT) and total protein (TP) remained in a normal range, which suggested $7 \mathbf{i}$ scarcely causes any serious hepatotoxicity (Figure 3, Table 4).

Figure 2. (a) Body weights of DIO mice, either HFD group $(n=5)$ or treated groups $(n=5)$, were monitored during the oral administration of metformin $(150 \mathrm{mg} / \mathrm{kg} / \mathrm{day})$ and $7 \mathbf{i}$ $(50 \mathrm{mg} / \mathrm{kg} /$ day) for 5 weeks; (b) Average body weight gain; (c) liver weight, and (d) Food intake: ${ }^{*}, p<0.05,{ }^{* *}, p<0.01, v s$. HFD.
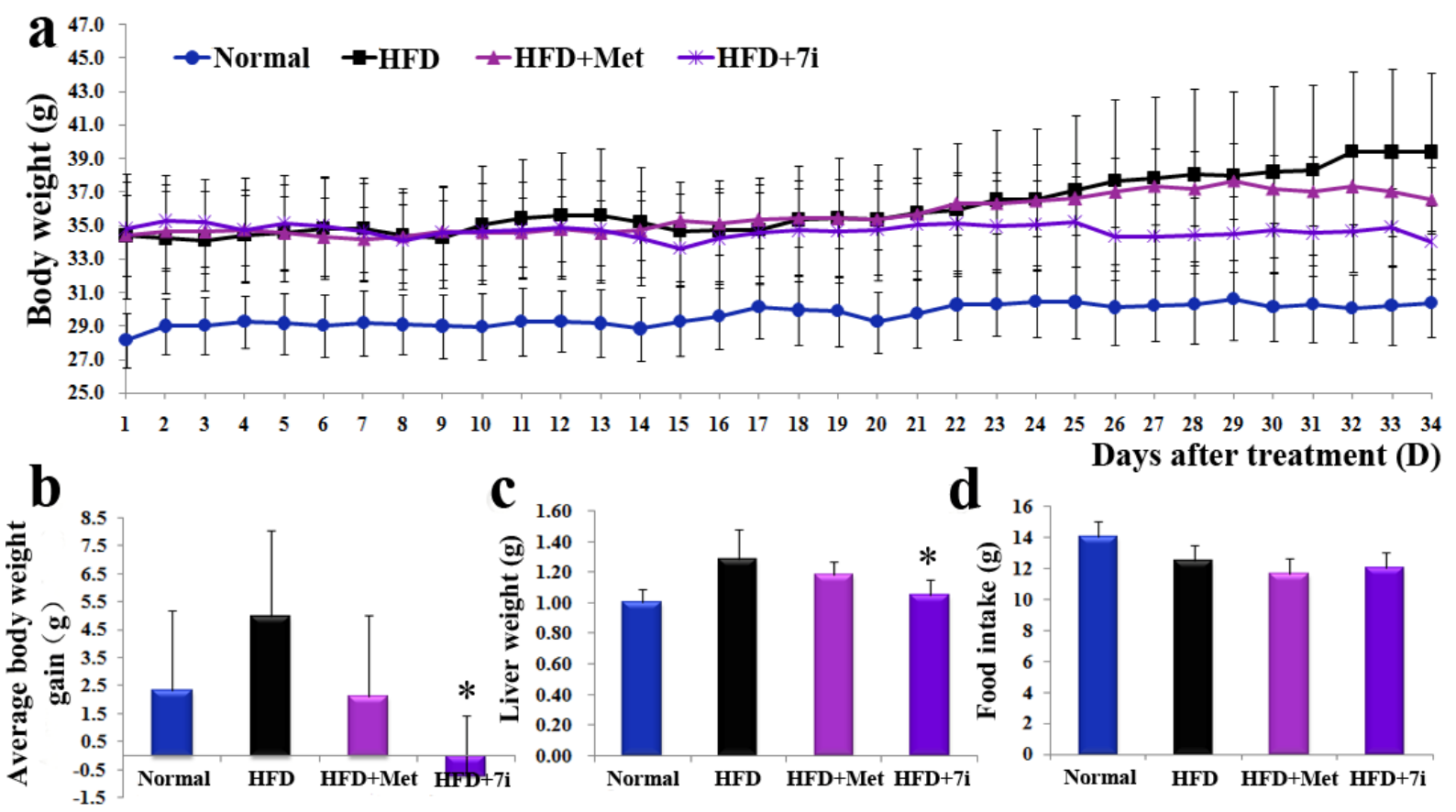
Figure 3. (a) Serum leptin level of DIO mice; (b) Serum adiponectin level of DIO mice; (c) Serum triglyceride; (d) total cholesterol: ${ }^{*}, p<0.05, * *, p<0.01, v s$. HFD.
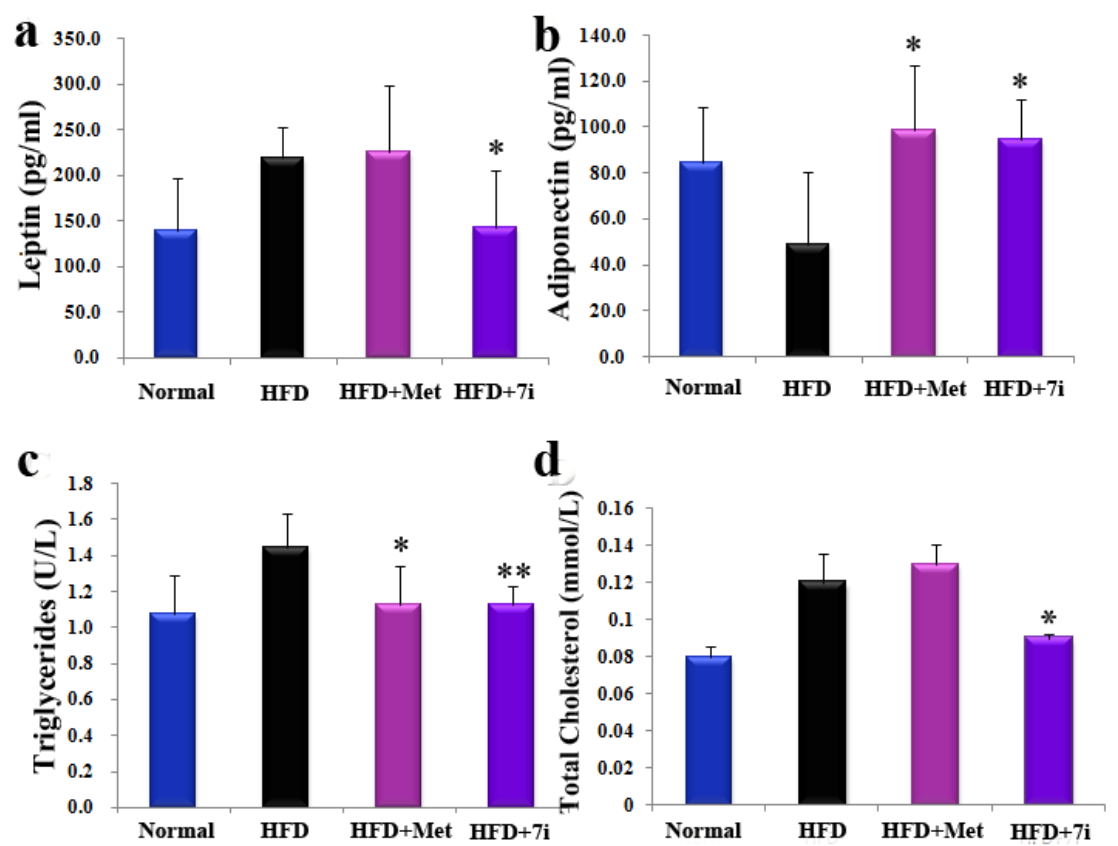

Table 4. Parameters of Serum Biochemical Markers from DIO mice ${ }^{\text {a }}$.

\begin{tabular}{ccccc}
\hline Parameter & Normal & HFD & HFD + Met & HFD + 7i \\
\hline LDL-c (mM) & 0.2 & 0.3 & $0.2 \pm 0.1$ & $0.1 * *$ \\
HDL-c (mM) & $1.6 \pm 0.4$ & $2.8 \pm 0.6$ & $3.0 \pm 0.9$ & $2.2 *$ \\
ALT (U/L) & $35.0 \pm 12.7$ & $44.0 \pm 9.6$ & $34.0 \pm 17.8$ & $36.0 \pm 9.6$ \\
AST (U/L) & $96.0 \pm 30.1$ & $105.0 \pm 10.0$ & $121.0 \pm 30.9$ & $126.0 \pm 23.6$ \\
TP (g/L) & $51.9 \pm 3.3$ & $53.1 \pm 3.4$ & $57.1 \pm 6.3$ & $55.8 \pm 3.7$ \\
\hline
\end{tabular}

${ }^{\mathrm{a}}$ The HFD-fed $(n=5)$ or treated groups $(n=5)$ were respectively monitored during the oral administration of Met $(150 \mathrm{mg} / \mathrm{kg} / \mathrm{day})$ and $7 \mathbf{i}(50 \mathrm{mg} / \mathrm{kg} /$ day $)$ for 5 weeks. The results were expressed as the mean $\pm \mathrm{SD}$ : *, $p<0.05, * *, p<0.01, v s$. HFD.

\subsection{Histopathological Evaluation}

The effect of $7 \mathbf{i}$ in protecting the liver from the progression of obesity-related fat accumulation and hepatic steatosis was further verified by hematoxylin-eosin (H\&E) and Oil Red O staining assay [36,37]. As shown in Figure 4, DIO in C57/B16 mice is accompanied by an obvious fat deposition (steatosis) and a remarkable increase in adipocyte size in the liver tissues compared to the normal group, while a remarkable reduction of lipid droplets (black arrowheads) was observed, which means that there was an obvious restriction of the fat accumulation in the section of liver tissue after treatment with $7 \mathbf{i}$ (Figure 4a,b). Meanwhile, the adipocytes were smaller in size than those of the model group and tended to normal levels (Figure 4c). The metformin-treated group showed weaker potency in ameliorating both the fat deposition and the size of adipocytes compared to $7 \mathbf{i}$. 
Figure 4. (a), (b) H\&E staining and Oil Red O of liver tissue (scale, 200×). (c) H\&E staining of fat tissue from DIO rats (scale, 100×). Lipid droplets are marked using black arrowheads.

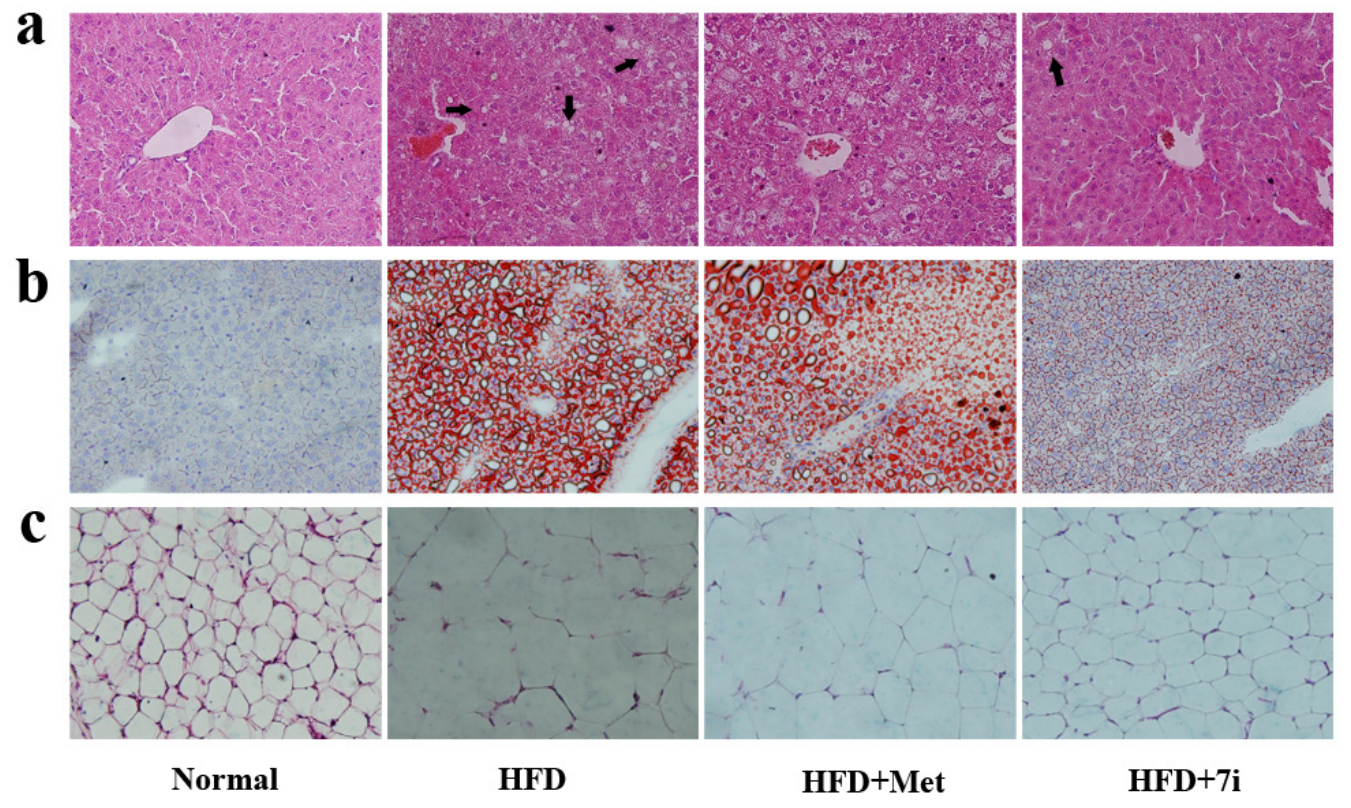

\section{Experimental}

\subsection{General Information}

Chemistry reagents of analytical grade were purchased from Changzheng Chemical Factory, (Chengdu, China). TLC was performed on $0.20 \mathrm{~mm}$ Silica Gel $60 \mathrm{~F}_{254}$ plates (Qingdao Ocean Chemical Factory, Shandong, China). ${ }^{1} \mathrm{H}$ - and ${ }^{13} \mathrm{C}-\mathrm{NMR}$ spectra were recorded at $400 \mathrm{MHz}$ and $100 \mathrm{MHz}$, respectively, on a Varian model Gemini 400 spectrometer (Varian, Palo Alto, CA, USA). Chemical shifts $(\delta)$ are quoted in ppm relative to tetramethylsilane (TMS) as an internal standard, where $(\delta)$ TMS $=0.00 \mathrm{ppm}$. The multiplicity of the signal is indicated as s, singlet; d, doublet; $\mathrm{t}$, triplet; q, quartet; $\mathrm{m}$, multiplet, defined as all multipeak signals where overlap or complex coupling of signals makes definitive descriptions of peaks difficult. Mass Spectra (MS) were measured on a Q-TOF Premier mass spectrometer (Micromass, Manchester, UK) electrospray ionization (ESI).

\subsection{Chemistry}

\subsubsection{Synthesis of tert-Butyl (1-(4-nitrobenzyl)piperidin-4-yl)carbamate (3)}

4-(tert-Butoxycarbonylamino)piperidine $(10.5 \mathrm{mmol})$, nitrobenzyl bromide $(10.0 \mathrm{mmol})$, and potassium carbonate $(30.0 \mathrm{mmol})$ in acetone $(60 \mathrm{~mL})$ were stirred at $60{ }^{\circ} \mathrm{C}$ for $4 \mathrm{~h}$. After the reaction was complete, the mixture was concentrated under reduced pressure, and the residue was poured into water $(100 \mathrm{~mL})$ to afford a pure light yellow solid which was collected by filtration, washed with water, and then dried for the further use without any additional purification. Yield 95.2\%; Yellow solid; ${ }^{1} \mathrm{H}-\mathrm{NMR}$ $\left(\mathrm{DMSO}_{-} d_{6}\right): \delta 8.18(\mathrm{~d}, 2 \mathrm{H}, J=8.4 \mathrm{~Hz}), 7.51(\mathrm{~d}, 2 \mathrm{H}, J=8.0 \mathrm{~Hz}), 4.44(\mathrm{~m}, 1 \mathrm{H}), 3.58-3.49(\mathrm{~m}, 3 \mathrm{H})$, $2.77(\mathrm{~m}, 2 \mathrm{H}), 2.15(\mathrm{~m}, 2 \mathrm{H}), 1.95-1.92(\mathrm{~m}, 2 \mathrm{H}), 1.44-1.42(\mathrm{~m}, 11 \mathrm{H})$; MS (ESI), $m / z: 336.18[\mathrm{M}+\mathrm{H}]^{+}$. 


\subsubsection{General Procedure for the Synthesis of Compounds 4}

To a solution of $3(1.0 \mathrm{mmol})$ in DCM $(1 \mathrm{~mL})$ was added TFA $(1 \mathrm{~mL})$ at $0{ }^{\circ} \mathrm{C}$. The resulting brownish orange solution is warmed to room temperature and stirred for $3 \mathrm{~h}$ and then concentrated in vacuo to afford a brown oil. The residue was treated with diethyl ether $(50 \mathrm{~mL})$ to yield a white solid which was isolated by filtration.

\subsubsection{General Procedure for the Synthesis of Compounds $\mathbf{5}$ and $\mathbf{1 2}$}

To a solution of substituted benzoic acid $(2.0 \mathrm{mmol})$, EDCI (1.5 mmol) and DMAP (1.0 mmol) in DCM $(10 \mathrm{~mL}), 4(2.0 \mathrm{mmol})$ was added and the mixture stirred at room temperature for $14 \mathrm{~h}$. The reaction mixture was then extracted with DCM and water, and the organic layer was washed with brine and dried over anhydrous sodium sulfate. The solvent was removed under reduced pressure. The residue was purified by column chromatography on silica gel to afford the title compounds.

\subsubsection{General Procedure for the Synthesis of Compounds $\mathbf{6}$ and $\mathbf{1 3}$}

A solution of the $5(1 \mathrm{mmol})$ in anhydrous $\mathrm{EtOH}$ was treated with solid $\mathrm{SnCl}_{2} \cdot 2 \mathrm{H}_{2} \mathrm{O}(7 \mathrm{mmol})$. The mixture was stirred at $80{ }^{\circ} \mathrm{C}$ for $1.5 \mathrm{~h}$ and then poured cautiously into saturated aqueous $\mathrm{K}_{2} \mathrm{CO}_{3}$. The resulting gelatinous emulsion was filtered through a pad of Celite, washed with DCM and the biphasic filtrate was extracted with DCM. The combined organic extracts were dried $\left(\mathrm{Na}_{2} \mathrm{SO}_{4}\right)$ and concentrated in vacuo, affording the anilines without further purification.

N-(1-(4-Aminobenzyl)piperidin-4-yl)-3-(trifluoromethyl)benzamide (6a). Yield 75.2\%; Yellow solid; ${ }^{1} \mathrm{H}-\mathrm{NMR}\left(\mathrm{DMSO}-d_{6}\right): \delta 8.02(\mathrm{~s}, 1 \mathrm{H}), 7.93(\mathrm{~d}, 1 \mathrm{H}, J=7.6 \mathrm{~Hz}), 7.75(\mathrm{~d}, 1 \mathrm{H}, J=7.6 \mathrm{~Hz}), 7.57(\mathrm{t}, 1 \mathrm{H}$, $J=8.0 \mathrm{~Hz}), 7.12(\mathrm{~d}, 2 \mathrm{H}, J=8.0 \mathrm{~Hz}), 6.66(\mathrm{~d}, 2 \mathrm{H}, J=8.0 \mathrm{~Hz}), 6.17(\mathrm{~d}, 2 \mathrm{H}, J=7.6 \mathrm{~Hz}), 4.05-4.02(\mathrm{~m}$, $1 \mathrm{H}), 3.50(\mathrm{~s}, 2 \mathrm{H}), 2.95(\mathrm{~m}, 2 \mathrm{H}), 2.22(\mathrm{~m}, 2 \mathrm{H}), 2.03(\mathrm{~m}, 2 \mathrm{H}), 1.71-1.65(\mathrm{~m}, 2 \mathrm{H}) ; \mathrm{MS}(\mathrm{ESI}), \mathrm{m} / z: 378.17$ $[\mathrm{M}+\mathrm{H}]^{+}$.

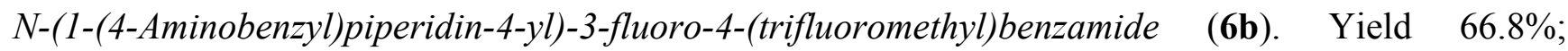
Yellow solid; ${ }^{1} \mathrm{H}-\mathrm{NMR}\left(\mathrm{DMSO}-d_{6}\right): \delta 7.69-7.58(\mathrm{~m}, 3 \mathrm{H}), 7.12(\mathrm{~d}, 2 \mathrm{H}, J=8.0 \mathrm{~Hz}), 7.66(\mathrm{~d}, 2 \mathrm{H}$, $J=8.4 \mathrm{~Hz}), 6.13(\mathrm{~m}, 1 \mathrm{H}), 4.03-4.01(\mathrm{~m}, 1 \mathrm{H}), 3.67(\mathrm{~s}, 2 \mathrm{H}), 2.94(\mathrm{~m}, 2 \mathrm{H}), 2.12(\mathrm{~m}, 2 \mathrm{H}), 2.03(\mathrm{~m}, 2 \mathrm{H})$, $1.68(\mathrm{~m}, 2 \mathrm{H}) ; \mathrm{MS}(\mathrm{ESI}), m / z: 396.16[\mathrm{M}+\mathrm{H}]^{+}$.

N-(1-(4-Aminobenzyl)piperidin-4-yl)-4-chloro-2-methoxybenzamide (6c). Yield 65.2\%; Yellow solid; ${ }^{1} \mathrm{H}-\mathrm{NMR}\left(\mathrm{DMSO}-d_{6}\right): \delta 8.16(\mathrm{~d}, 2 \mathrm{H}, J=2.8 \mathrm{~Hz}), 7.77(\mathrm{~d}, 1 \mathrm{H}, J=7.6 \mathrm{~Hz}), 7.37(\mathrm{dd}, 1 \mathrm{H}, J=8.8 \mathrm{~Hz}$, $J=2.8 \mathrm{~Hz}), 7.85-7.81(\mathrm{~m}, 1 \mathrm{H}), 7.10(\mathrm{~d}, 1 \mathrm{H}, J=8.0 \mathrm{~Hz}), 6.90(\mathrm{~d}, 1 \mathrm{H}, J=8.8 \mathrm{~Hz}), 6.65(\mathrm{~d}, 2 \mathrm{H}$, $J=8.4 \mathrm{~Hz}), 4.05-4.03(\mathrm{~m}, 1 \mathrm{H}), 3.91(\mathrm{~s}, 3 \mathrm{H}), 3.64(\mathrm{brs}, 2 \mathrm{H}), 3.42(\mathrm{~s}, 2 \mathrm{H}), 2.78(\mathrm{~m}, 2 \mathrm{H}), 2.18(\mathrm{~m}, 2 \mathrm{H})$, 2.02-1.98 (m, 2H), 1.57-1.55 (m, 2H); MS (ESI), $m / z: 374.16[\mathrm{M}+\mathrm{H}]^{+}$.

$N$-(1-(4-Aminobenzyl)piperidin-4-yl)-2,2-difluorobenzo[d][1,3]dioxole-4-carboxamide (6d). Yield 63.0\%; Yellow solid; ${ }^{1} \mathrm{H}-\mathrm{NMR}\left(\mathrm{DMSO}-d_{6}\right): \delta 7.67(\mathrm{dd}, 1 \mathrm{H}, J=6.4 \mathrm{~Hz}, J=2.8 \mathrm{~Hz}$ ), $7.11-7.07$ (m, $4 \mathrm{H}), 6.59$ (d, 2H, $J=8.0 \mathrm{~Hz}), 6.50$ (d, 2H, $J=7.6 \mathrm{~Hz}), 4.02(\mathrm{~m}, 1 \mathrm{H}), 3.50$ (s, 2H), 2.92 (d, 2H, $J=9.6 \mathrm{~Hz})$, $2.25(\mathrm{t}, 2 \mathrm{H}, J=10.8 \mathrm{~Hz}), 2.00(\mathrm{~d}, 2 \mathrm{H}, J=10.4 \mathrm{~Hz}), 1.77-1.72(\mathrm{~m}, 2 \mathrm{H})$; MS (ESI), $m / z: 390.16[\mathrm{M}+\mathrm{H}]^{+}$. 
N-(1-(4-Aminobenzyl)piperidin-4-yl)-3-(1,1,2,2-tetrafluoroethyl)benzamide (6e). Yield 65.2\%; Yellow solid; ${ }^{1} \mathrm{H}-\mathrm{NMR}$ (DMSO- $\left.d_{6}\right): \delta 7.64-7.62(\mathrm{~m}, 2 \mathrm{H}), 7.45(\mathrm{t}, 1 \mathrm{H}, J=8.0 \mathrm{~Hz}), 7.13(\mathrm{~d}, 2 \mathrm{H}, J=7.6 \mathrm{~Hz})$, $6.66(\mathrm{~d}, 2 \mathrm{H}, J=7.6 \mathrm{~Hz}), 6.09-5.80(\mathrm{~m}, 2 \mathrm{H}), 4.02(\mathrm{~m}, 1 \mathrm{H}), 3.68(\mathrm{~s}, 2 \mathrm{H}), 2.97$ (d, 2H, J=10.0 Hz), 2.25 (t, $2 \mathrm{H}, J=12.0 \mathrm{~Hz}), 2.04(\mathrm{~d}, 2 \mathrm{H}, J=11.2 \mathrm{~Hz}), 1.74-1.72(\mathrm{~m}, 2 \mathrm{H})$; MS (ESI), $m / z: 410.18[\mathrm{M}+\mathrm{H}]^{+}$.

N-(1-(4-Aminobenzyl)piperidin-4-yl)-4-(difluoromethoxy)benzamide (6f). Yield 76.2\%; Yellow solid; ${ }^{1} \mathrm{H}-\mathrm{NMR}\left(\mathrm{DMSO}-d_{6}\right): \delta 7.91(\mathrm{~d}, 2 \mathrm{H}, J=8.4 \mathrm{~Hz}), 7.45(\mathrm{~d}, 2 \mathrm{H}, J=6.4 \mathrm{~Hz}), 7.20(\mathrm{~d}, 1 \mathrm{H}, J=8.0 \mathrm{~Hz})$, $7.13(\mathrm{~d}, 2 \mathrm{H}, J=8.4 \mathrm{~Hz}), 6.83-6.47$ (m, 3H), 4.06 (brs, 2H), 3.73 (s, 2H), 2.92 (d, 2H, $J=10.8 \mathrm{~Hz})$, $2.48(\mathrm{~m}, 2 \mathrm{H}), 2.03-1.99(\mathrm{~m}, 24 \mathrm{H})$; MS (ESI), $m / z: 376.18[\mathrm{M}+\mathrm{H}]^{+}$.

$N-\left(1-(4-A m i n o b e n z y l)\right.$ piperidin-4-yl)nicotinamide (6g). Yield 45.2\%; Yellow solid; ${ }^{1} \mathrm{H}-\mathrm{NMR}$ (DMSO- $d_{6}$ ): $\delta 8.55(\mathrm{~d}, 2 \mathrm{H}, J=4.4 \mathrm{~Hz}), 8.17(\mathrm{~d}, 1 \mathrm{H}, J=8.0 \mathrm{~Hz}), 8.03(\mathrm{~d}, 1 \mathrm{H}, J=7.2 \mathrm{~Hz}), 7.85-7.81(\mathrm{~m}, 1 \mathrm{H})$, $7.43-7,20(\mathrm{~m}, 1 \mathrm{H}), 7.20(\mathrm{~d}, 2 \mathrm{H}, J=7.2 \mathrm{~Hz}), 6.69(\mathrm{~d}, 2 \mathrm{H}, J=8.4 \mathrm{~Hz}), 5.99(\mathrm{~m}, 1 \mathrm{H}), 4.04(\mathrm{~m}, 1 \mathrm{H}), 3.65$ (m, 4H), 3.07 (m, 2H), 2.41-2.39 (m, 2H); MS (ESI), $m / z: 310.18[\mathrm{M}+\mathrm{H}]^{+}$.

N-(1-(4-Aminobenzyl)piperidin-4-yl)-5-methylpyrazine-2-carboxamide (6h). Yield 75.2\%; Yellow solid; ${ }^{1} \mathrm{H}-\mathrm{NMR}$ (DMSO-d $\left.)_{6}\right): \delta .25(\mathrm{~s}, 1 \mathrm{H}), 8.37(\mathrm{~s}, 1 \mathrm{H}), 7.66(\mathrm{~d}, 2 \mathrm{H}, J=8.0 \mathrm{~Hz}), 7.10(\mathrm{~d}, 2 \mathrm{H}$, $J=8.4 \mathrm{~Hz}$ ), 6.65 (d, 2H, $J=8.4 \mathrm{~Hz}), 4.04-3.96$ (m, 1H), 3.65 (brs, 2H), 3.43 (s, 2H), 2.86 (d, 2H, $J=11.2 \mathrm{~Hz}), 2.64(\mathrm{~s}, 2 \mathrm{H}), 2.17(\mathrm{t}, 2 \mathrm{H}, J=11.2 \mathrm{~Hz}), 1.99$ (d, 2H, $J=10.8 \mathrm{~Hz}), 1.67-1.58(\mathrm{~m}, 2 \mathrm{H})$; MS (ESI), $m / z: 326.19[\mathrm{M}+\mathrm{H}]^{+}$.

(4-(4-Aminophenoxy)piperidin-1-yl)(3-fluoro-4-(trifluoromethyl)phenyl) methanone (13a). Yield 55.2\%; Yellow solid; ${ }^{1} \mathrm{H}-\mathrm{NMR}\left(\mathrm{DMSO}-d_{6}\right): \delta 7.67(\mathrm{t}, 1 \mathrm{H}, J=7.6 \mathrm{~Hz}), 7.29-7.24(\mathrm{~m}, 2 \mathrm{H}), 6.77(\mathrm{~d}, 2 \mathrm{H}$, $J=8.4 \mathrm{~Hz}), 6.64$ (d, 2H, $J=8.4 \mathrm{~Hz}), 4.44-4.39(\mathrm{~m}, 1 \mathrm{H}), 3.85(\mathrm{~s}, 2 \mathrm{H}), 3.61(\mathrm{~m}, 1 \mathrm{H}), 3.31(\mathrm{~m}, 1 \mathrm{H})$, $1.94-1.80(\mathrm{~m}, 4 \mathrm{H})$; MS (ESI), $m / z: 383.13[\mathrm{M}+\mathrm{H}]^{+}$.

4-((1-((4-Fluorophenyl)sulfonyl)piperidin-4-yl)oxy)aniline (13b). Yield 60.2\%; Yellow solid; ${ }^{1} \mathrm{H}-\mathrm{NMR}\left(\mathrm{DMSO}-d_{6}\right): \delta 7.81-7.77(\mathrm{~m}, 2 \mathrm{H}), 7.62-7.53(\mathrm{~m}, 1 \mathrm{H}), 7.25-7.21(\mathrm{~m}, 1 \mathrm{H}), 6.66-6.63(\mathrm{~m}, 2 \mathrm{H})$, 6.61-6,57 (m, 4H) 4.22-4.18 (m, 1H), 3.17-3.10 (m, 1H), 1.97-1.87 (m, 4H); MS (ESI), m/z: 351.11 $[\mathrm{M}+\mathrm{H}]^{+}$.

\subsubsection{General Procedure for the Synthesis of Compounds $7 \mathbf{a}-7 \mathbf{i}, \mathbf{8}, \mathbf{1 4 a}, \mathbf{1 4 b}, \mathbf{1 4 d}$}

Ethyl isocyanate $(3.6 \mathrm{mmol})$ was added dropwise to a stirred solution of the relevant aniline $\mathbf{6}$ or $\mathbf{1 3}$ ( $3 \mathrm{mmol})$ in DCM $(15 \mathrm{~mL})$. The reaction mixture was stirred overnight at ambient temperature. The resulting crude precipitate was filtered, washed with cold ether, and purified by recrystallization from ethanol and water.

N-(1-(4-(3-Ethylureido)benzyl)piperidin-4-yl)-3-(trifluoromethyl)benzamide (7a). Yield 55.2\%; White solid; ${ }^{1} \mathrm{H}-\mathrm{NMR}$ (DMSO- $\left.d_{6}\right): \delta 8.52(\mathrm{~d}, 1 \mathrm{H}, J=8.0 \mathrm{~Hz}), 8.35(\mathrm{~m}, 2 \mathrm{H}), 8.15(\mathrm{~s}, 1 \mathrm{H}), 7.99(\mathrm{~d}, 1 \mathrm{H}$, $J=8.0 \mathrm{~Hz}), 7.71(\mathrm{t}, 2 \mathrm{H}, J=8.0 \mathrm{~Hz}), 7.32(\mathrm{~d}, 2 \mathrm{H}, J=8.0 \mathrm{~Hz}), 7.13(\mathrm{~d}, 2 \mathrm{H}, J=8.0 \mathrm{~Hz}), 6.05(\mathrm{t}, 1 \mathrm{H}$, $J=4.0 \mathrm{~Hz}), 3.77(\mathrm{~m}, 1 \mathrm{H}), 3.37(\mathrm{~s}, 2 \mathrm{H}), 3.06(\mathrm{~m}, 2 \mathrm{H}), 2.82(\mathrm{~d}, 2 \mathrm{H}, J=12.0 \mathrm{~Hz}), 1.98(\mathrm{t}, 2 \mathrm{H}, J=12.0 \mathrm{~Hz})$, $1.77(\mathrm{~m}, 2 \mathrm{H}), 1.55(\mathrm{~m}, 2 \mathrm{H}), 1.04(\mathrm{t}, 2 \mathrm{H}, J=8.0 \mathrm{~Hz})$; HRMSMS (ESI), $m / z: 449.2086[\mathrm{M}+\mathrm{H}]^{+}$. 
N-(1-(4-(3-Allylureido)benzyl)piperidin-4-yl)-3-(trifluoromethyl)benzamide (7b). Yield 54.9\%; White solid; ${ }^{1} \mathrm{H}-\mathrm{NMR}\left(\mathrm{DMSO}-d_{6}\right): \delta 8.52(\mathrm{~d}, 1 \mathrm{H}, J=4.0 \mathrm{~Hz}), 8.45(\mathrm{~s}, 1 \mathrm{H}), 8.17-8.13(\mathrm{~m}, 1 \mathrm{H}), 7.89(\mathrm{~d}, 1 \mathrm{H}$, $J=8.0 \mathrm{~Hz}), 7.71-7.59(\mathrm{~m}, 1 \mathrm{H}), 7.33(\mathrm{~d}, 2 \mathrm{H}, J=8.0 \mathrm{~Hz}), 7.14(\mathrm{~d}, 2 \mathrm{H}, J=8.0 \mathrm{~Hz}), 6.22(\mathrm{~m}, 1 \mathrm{H})$, $5.87-5.85(\mathrm{~m}, 1 \mathrm{H}), 5.16(\mathrm{~d}, 1 \mathrm{H}, J=16.0 \mathrm{~Hz}), 5.06(\mathrm{~d}, 1 \mathrm{H}, J=12.0 \mathrm{~Hz}), 3.77-3.72(\mathrm{~m}, 3 \mathrm{H}), 3.37$ (s, 2H), $2.82(\mathrm{~d}, 2 \mathrm{H}, J=12.0 \mathrm{~Hz}), 1.99(\mathrm{t}, 2 \mathrm{H}, J=12.0 \mathrm{~Hz}), 1.78(\mathrm{~m}, 2 \mathrm{H}), 1.58(\mathrm{t}, 2 \mathrm{H}, J=12.0 \mathrm{~Hz})$; HRMS (ESI), $m / z: 461.2086[\mathrm{M}+\mathrm{H}]^{+}$.

N-(1-(4-(3-Ethylureido)benzyl)piperidin-4-yl)-3-fluoro-4-(trifluoromethyl)benzamide $\quad$ (7c). Yield 44.2\%; White solid; ${ }^{1} \mathrm{H}-\mathrm{NMR}\left(\mathrm{DMSO}-d_{6}\right): \delta 8.55(\mathrm{~d}, 1 \mathrm{H}, J=8.0 \mathrm{~Hz}), 8.37(\mathrm{~s}, 1 \mathrm{H}), 7.91-7.81(\mathrm{~m}, 2 \mathrm{H})$, $7.32(\mathrm{~d}, 1 \mathrm{H}, J=8.0 \mathrm{~Hz}), 6.07-6.05(\mathrm{~m}, 1 \mathrm{H}), 3.75(\mathrm{~m}, 2 \mathrm{H}), 3.09-3.06(\mathrm{~m}, 2 \mathrm{H}), 2.80(\mathrm{~m}, 2 \mathrm{H}), 1.99(\mathrm{~m}$, 2H), $1.77(\mathrm{~m}, 2 \mathrm{H}), 1.57-1.54(\mathrm{~m}, 2 \mathrm{H}) 1.04$ (t, 2H, $J=8.0 \mathrm{~Hz})$; HRMS (ESI), $m / z: 467.1992[\mathrm{M}+\mathrm{H}]^{+}$.

N-(1-(4-(3-Ethylureido)benzyl)piperidin-4-yl)-5-methylpyrazine-2-carboxamide (7d). Yield 47.8\%; White solid; ${ }^{1} \mathrm{H}-\mathrm{NMR}\left(\mathrm{CD}_{3} \mathrm{OD}\right): \delta 9.07(\mathrm{~s}, 1 \mathrm{H}), 8.57(\mathrm{~s}, 1 \mathrm{H}), 7.49(\mathrm{~d}, 2 \mathrm{H}, J=8.4 \mathrm{~Hz}), 7.39(\mathrm{~d}, 2 \mathrm{H}$, $J=8.4 \mathrm{~Hz}), 4.23(\mathrm{~m}, 3 \mathrm{H}), 3.48(\mathrm{~m}, 3 \mathrm{H}), 3.23(\mathrm{q}, 2 \mathrm{H}, J=7.2 \mathrm{~Hz}), 3.13(\mathrm{~m}, 2 \mathrm{H}), 2.63(\mathrm{~s}, 3 \mathrm{H}), 2.20-2.17$ $(\mathrm{m}, 2 \mathrm{H}), 2.01-1.98(\mathrm{~m}, 2 \mathrm{H}) 1.15(\mathrm{t}, 2 \mathrm{H}, J=7.2 \mathrm{~Hz})$; HRMS (ESI), $m / z: 397.2274[\mathrm{M}+\mathrm{H}]^{+}$.

4-Chloro-N-(1-(4-(3-ethylureido)benzyl)piperidin-4-yl)-2-methoxybenzamide (7e). Yield 39.5\%; White solid; ${ }^{1} \mathrm{H}-\mathrm{NMR}$ (DMSO- $\left.d_{6}\right): \delta 7.75(\mathrm{~d}, 1 \mathrm{H}, J=2.4 \mathrm{~Hz}), 7.45(\mathrm{dd}, 1 \mathrm{H}, J=8.8 \mathrm{~Hz}, J=2.8 \mathrm{~Hz}), 7.33(\mathrm{~d}$, $2 \mathrm{H}, J=8.4 \mathrm{~Hz}), 7.22(\mathrm{~d}, 2 \mathrm{H}, J=8.4 \mathrm{~Hz}), 7.12(\mathrm{~d}, 1 \mathrm{H}, J=8.8 \mathrm{~Hz}), 3.92(\mathrm{~s}, 4 \mathrm{H}), 3.50(\mathrm{~s}, 2 \mathrm{H}), 3.22(\mathrm{q}$, $2 \mathrm{H}, J=7.2 \mathrm{~Hz}), 2.84(\mathrm{~d}, 2 \mathrm{H}, J=10.0 \mathrm{~Hz}), 2.24(\mathrm{~m}, 2 \mathrm{H}), 1.96(\mathrm{~d}, 2 \mathrm{H}, J=10.0 \mathrm{~Hz}), 1.62(\mathrm{~m}, 2 \mathrm{H}), 1.14$ (t, $2 \mathrm{H}, J=11.2 \mathrm{~Hz})$; HRMS (ESI), $m / z: 445.1928[\mathrm{M}+\mathrm{H}]^{+}$.

N-(1-(4-(3-Allylureido)benzyl)piperidin-4-yl)-4-chloro-2-methoxybenzamide (7f). Yield 57.7\%; White solid; ${ }^{1} \mathrm{H}-\mathrm{NMR}\left(\mathrm{CD}_{3} \mathrm{OD}\right): \delta 7.84(\mathrm{~d}, 1 \mathrm{H}, J=4.0 \mathrm{~Hz}), 7.44(\mathrm{dd}, 1 \mathrm{H}, J=8.8 \mathrm{~Hz}, J=2.8 \mathrm{~Hz}), 7.35(\mathrm{~d}$, $2 \mathrm{H}, J=8.8 \mathrm{~Hz}), 7.22(\mathrm{~d}, 2 \mathrm{H}, J=8.8 \mathrm{~Hz}), 7.08(\mathrm{~d}, 1 \mathrm{H}, J=8.8 \mathrm{~Hz}), 5.93-5.87(\mathrm{~m}, 1 \mathrm{H}), 5.22(\mathrm{dd}, 1 \mathrm{H}$, $J=17.2 \mathrm{~Hz}, J=1.6 \mathrm{~Hz}), 5.11(\mathrm{dd}, 1 \mathrm{H}, J=17.2 \mathrm{~Hz}, J=1.6 \mathrm{~Hz}), 3.93(\mathrm{~s}, 3 \mathrm{H}), 3.82(\mathrm{~d}, 2 \mathrm{H}, J=5.2 \mathrm{~Hz})$, $3.51(\mathrm{~s}, 2 \mathrm{H}), 2.84(\mathrm{~d}, 2 \mathrm{H}, J=9.6 \mathrm{~Hz}), 2.24(\mathrm{t}, 2 \mathrm{H}, J=9.6 \mathrm{~Hz}), 1.98(\mathrm{~d}, 2 \mathrm{H}, J=10.8 \mathrm{~Hz}), 1.62(\mathrm{q}, 2 \mathrm{H}$, $J=10.0 \mathrm{~Hz}$ ); HRMS (ESI), $m / z: 457.1928[\mathrm{M}+\mathrm{H}]^{+}$.

4-Chloro-N-(1-(4-(3-(2-chloroethyl)ureido)benzyl)piperidin-4-yl)-2-methoxybenzamide (7g). Yield 60.2\%; White solid; ${ }^{1} \mathrm{H}-\mathrm{NMR}$ (DMSO- $\left.d_{6}\right): \delta 8.62(\mathrm{~s}, 1 \mathrm{H}), 8.06(\mathrm{~d}, 1 \mathrm{H}, J=7.6 \mathrm{~Hz}), 7.59$ (d, $\left.1 \mathrm{H}, J=2.8 \mathrm{~Hz}\right), 7.49$ $(\mathrm{dd}, 1 \mathrm{H}, J=8.4 \mathrm{~Hz}, J=2.8 \mathrm{~Hz}), 7.34(\mathrm{~d}, 2 \mathrm{H}, J=8.4 \mathrm{~Hz}), 7.16-7.14(\mathrm{~m}, 3 \mathrm{H}), 6.39(\mathrm{t}, 1 \mathrm{H}, J=5.6 \mathrm{~Hz})$, $3.86(\mathrm{~s}, 3 \mathrm{H}), 3.83-3.77(\mathrm{~m}, 1 \mathrm{H}), 3.65(\mathrm{t}, 2 \mathrm{H}, J=6.4 \mathrm{~Hz}), 2.72(\mathrm{~d}, 2 \mathrm{H}, J=10.4 \mathrm{~Hz}), 2.06(\mathrm{~m}, 2 \mathrm{H}), 1.77$ (m, 2H), $1.51(\mathrm{~m}, 2 \mathrm{H})$; HRMS (ESI), $\mathrm{m} / z: 479.1538[\mathrm{M}+\mathrm{H}]^{+}$.

N-(1-(4-(3-(2-Chloroethyl)ureido)benzyl)piperidin-4-yl)-3-fluoro-4-(trifluoromethyl)benzamide (7h). Yield 44.5\%; White solid; ${ }^{1} \mathrm{H}-\mathrm{NMR}\left(\mathrm{DMSO}_{6}\right)$ ): $\delta 9.05(\mathrm{~s}, 1 \mathrm{H}), 8.85(\mathrm{bs}, 1 \mathrm{H}), 7.95-7.90(\mathrm{~m}, 2 \mathrm{H})$, 7.48-7.42 (m, 2H), $6.61(\mathrm{~m}, 1 \mathrm{H}), 4.11-3.99(\mathrm{~m}, 2 \mathrm{H}), 3.66(\mathrm{~m}, 2 \mathrm{H}), 3.42(\mathrm{~m}, 2 \mathrm{H}), 3.02(\mathrm{~m}, 2 \mathrm{H}), 1.94$ $(\mathrm{m}, 3 \mathrm{H}), 1.20(\mathrm{~m}, 2 \mathrm{H})$; HRMS (ESI), $m / z: 501.1602[\mathrm{M}+\mathrm{H}]^{+}$.

N-(1-(4-(3-(2-Chloroethyl)ureido)benzyl)piperidin-4-yl)-3-(trifluoromethyl)benzamide (7i). Yield 50.4\%; White solid; ${ }^{1} \mathrm{H}-\mathrm{NMR}\left(\mathrm{DMSO}-d_{6}\right): \delta 8.66(\mathrm{~s}, 1 \mathrm{H}), 8.54(\mathrm{~d}, 1 \mathrm{H}, J=8.0 \mathrm{~Hz}), 8.18-8.14(\mathrm{~m}, 2 \mathrm{H})$, $7.90(\mathrm{~d}, 1 \mathrm{H}, J=4.0 \mathrm{~Hz}), 7.69$ (t, 1H, $J=8.0 \mathrm{~Hz}), 7.35$ (d, 2H, $J=8.0 \mathrm{~Hz}), 7.17$ (d, 2H, $J=8.0 \mathrm{~Hz})$, 
$6.41(\mathrm{~s}, 1 \mathrm{H}), 3.79(\mathrm{~s}, 2 \mathrm{H}), 3.66(\mathrm{~m}, 2 \mathrm{H}), 3.42(\mathrm{~m}, 3 \mathrm{H}), 2.85(\mathrm{~s}, 2 \mathrm{H}), 2.01(\mathrm{~s}, 2 \mathrm{H}), 1.80(\mathrm{~m}, 2 \mathrm{H}), 1.61$ (m, 2H); HRMS (ESI), m/z: $483.1772[\mathrm{M}+\mathrm{H}]^{+}$.

N-(1-(4-(3-Ethylthioureido)benzyl)piperidin-4-yl)-3-(trifluoromethyl)benzamide (8a). Yield 64.2\%; White solid; ${ }^{1} \mathrm{H}-\mathrm{NMR}\left(\mathrm{CDCl}_{3}\right): \delta 8.01(\mathrm{~s}, 1 \mathrm{H}), 7.94(\mathrm{~d}, 1 \mathrm{H}, J=8.0 \mathrm{~Hz}), 7.93(\mathrm{~m}, 2 \mathrm{H}), 7.55(\mathrm{~m}, 2 \mathrm{H})$, 7.39 (d, $1 \mathrm{H}, J=8.0 \mathrm{~Hz}), 7.19$ (d, 2H, $J=8.0 \mathrm{~Hz}), 6.12-6.07(\mathrm{~m}, 2 \mathrm{H}), 4.04(\mathrm{~m}, 1 \mathrm{H}), 3.69-3.66(\mathrm{~m}$, $2 \mathrm{H}), 3.56(\mathrm{~s}, 2 \mathrm{H}), 2.92(\mathrm{~d}, 1 \mathrm{H}, J=12.0 \mathrm{~Hz}), 2.28-2.23(\mathrm{~m}, 3 \mathrm{H}), 2.06(\mathrm{~d}, 2 \mathrm{H}, J=12.0 \mathrm{~Hz}), 1.67-1.64$ $(\mathrm{m}, 2 \mathrm{H}), 1.20(\mathrm{t}, 2 \mathrm{H}, J=8.0 \mathrm{~Hz})$; HRMS (ESI), $m / z: 465.1858[\mathrm{M}+\mathrm{H}]^{+}$.

N-(1-(4-(3-Ethylthioureido)benzyl)piperidin-4-yl)-3-fluoro-4-(trifluoromethyl)benzamide (8b). Yield 35.2\%; White solid; ${ }^{1} \mathrm{H}-\mathrm{NMR}\left(\mathrm{CDCl}_{3}\right): \delta 7.62-7.60(\mathrm{~m}, 3 \mathrm{H}), 7.29(\mathrm{~d}, 1 \mathrm{H}, J=8.0 \mathrm{~Hz}), 7.17(\mathrm{~d}, 1 \mathrm{H}, J=$ $8.0 \mathrm{~Hz}), 3.93-3.92(\mathrm{~m}, 1 \mathrm{H}), 3.58(\mathrm{q}, 2 \mathrm{H}, J=8.0 \mathrm{~Hz}), 3.50(\mathrm{~s}, 2 \mathrm{H}), 2.90(\mathrm{~d}, 1 \mathrm{H}, J=12.0 \mathrm{~Hz}), 2.15(\mathrm{~m}$, $2 \mathrm{H}), 1.92(\mathrm{~d}, 2 \mathrm{H}, J=12.0 \mathrm{~Hz}), 1.65-1.55(\mathrm{~m}, 2 \mathrm{H}), 1.13(\mathrm{t}, 2 \mathrm{H}, J=8.0 \mathrm{~Hz})$; HRMS (ESI), $m / z$ : $483.1763[\mathrm{M}+\mathrm{H}]^{+}$.

4-Chloro-N-(1-(4-(3-ethylthioureido)benzyl)piperidin-4-yl)-2-methoxy benzamide (8c). Yield 65.2\%; White solid; ${ }^{1} \mathrm{H}-\mathrm{NMR}$ (DMSO- $d_{6}$ ): $\delta 9.46(\mathrm{bs}, 1 \mathrm{H}), 8.12$ (d, $\left.1 \mathrm{H}, J=7.2 \mathrm{~Hz}\right), 7.75(\mathrm{~s}, 1 \mathrm{H}), 7.65(\mathrm{~s}, 1 \mathrm{H})$, $7.54(\mathrm{~d}, 1 \mathrm{H}, J=7.2 \mathrm{~Hz}), 7.38(\mathrm{~d}, 2 \mathrm{H}, J=8.0 \mathrm{~Hz}), 7.28(\mathrm{~d}, 2 \mathrm{H}, J=8.0 \mathrm{~Hz}), 7.20(\mathrm{~d}, 1 \mathrm{H}, J=8.0 \mathrm{~Hz})$, 3.91-3.82 (m, 4H), 3.47-3.42 (m, 4H), $2.79(\mathrm{~d}, 2 \mathrm{H}, J=9.6 \mathrm{~Hz}), 2.13(\mathrm{~m}, 2 \mathrm{H}), 1.87(\mathrm{~m}, 2 \mathrm{H}), 1.57(\mathrm{~m}$, $2 \mathrm{H}), 1.16(\mathrm{t}, 2 \mathrm{H}, J=6.8 \mathrm{~Hz})$; HRMS (ESI), $m / z: 461.1700[\mathrm{M}+\mathrm{H}]^{+}$.

1-Ethyl-3-(4-((1-(3-fluoro-4-(trifluoromethyl)benzoyl)piperidin-4-yl)oxy)phenyl)urea (14a). Yield 35.2\%; White solid; ${ }^{1} \mathrm{H}-\mathrm{NMR}\left(\mathrm{CDCl}_{3}\right): \delta 7.67$ (t, $\left.1 \mathrm{H}, J=6.8 \mathrm{~Hz}\right), 7.19$ (d, 2H, $\left.J=8.8 \mathrm{~Hz}\right), 6.87$ (d, $2 \mathrm{H}, J=8.8 \mathrm{~Hz}), 6.26(\mathrm{~s}, 1 \mathrm{H}), 4.65-4.56(\mathrm{~m}, 2 \mathrm{H}), 3.87(\mathrm{~m}, 2 \mathrm{H}), 3.47(\mathrm{~m}, 2 \mathrm{H}), 2.87-2.37(\mathrm{~m}, 2 \mathrm{H})$, $1.95-1.84(\mathrm{~m}, 4 \mathrm{H}), 1.13(\mathrm{t}, 3 \mathrm{H}, J=7.2 \mathrm{~Hz})$; HRMS (ESI), $m / z: 454.1676[\mathrm{M}+\mathrm{H}]^{+}$.

1-(2-Chloroethyl)-3-(4-((1-(3-fluoro-4-(trifluoromethyl)benzoyl)piperidin-4-yl)oxy)phenyl)urea (14b). Yield 35.2\%; White solid; ${ }^{1} \mathrm{H}-\mathrm{NMR}\left(\mathrm{CDCl}_{3}\right): \delta 7.68(\mathrm{t}, 1 \mathrm{H}, J=6.8 \mathrm{~Hz}), 7.18(\mathrm{~d}, 2 \mathrm{H}, J=8.0 \mathrm{~Hz}), 6.86$ $(\mathrm{d}, 2 \mathrm{H}, J=8.0 \mathrm{~Hz}), 6.59(\mathrm{~s}, 1 \mathrm{H}), 5.27(\mathrm{~m}, 1 \mathrm{H}), 4.56-4.55(\mathrm{~m}, 1 \mathrm{H}), 3.87(\mathrm{~m}, 2 \mathrm{H}), 3.65-3.63(\mathrm{~m}, 2 \mathrm{H})$, 3.59-3.55 (m, 2H), $3.47(\mathrm{~m}, 1 \mathrm{H}), 2.05-1.84(\mathrm{~m}, 4 \mathrm{H})$; MS (ESI), $m / z: 488.13[\mathrm{M}+\mathrm{H}]^{+}$.

1-Ethyl-3-(4-((1-((4-fluorophenyl)sulfonyl)piperidin-4-yl)oxy)phenyl)urea (14d). Yield 55.2\%; White solid; ${ }^{1} \mathrm{H}-\mathrm{NMR}\left(\mathrm{DMSO}-d_{6}\right)$ : $\delta 8.16(\mathrm{~s}, 1 \mathrm{H}), 7.86-7.83(\mathrm{~m}, 1 \mathrm{H}), 7.76-7.73(\mathrm{~m}, 1 \mathrm{H}), 7.69-7.65(\mathrm{~m}, 1 \mathrm{H})$, $7.51(\mathrm{t}, 1 \mathrm{H}, J=7.2 \mathrm{~Hz}), 7.21(\mathrm{dd}, 2 \mathrm{H}, J=8.8 \mathrm{~Hz}, J=2.8 \mathrm{~Hz}), 6.74(\mathrm{dd}, 2 \mathrm{H}, J=8.8 \mathrm{~Hz}, J=3.2 \mathrm{~Hz})$, $5.94(\mathrm{~s}, 1 \mathrm{H}), 4.31-2.89(\mathrm{~m}, 1 \mathrm{H}), 3.22(\mathrm{~m}, 2 \mathrm{H}), 3.10-3.03(\mathrm{~m}, 2 \mathrm{H}), 2.84(\mathrm{t}, 2 \mathrm{H}, J=8.8 \mathrm{~Hz}), 1.93(\mathrm{~m}$, 2H), $1.65-1.63(\mathrm{~m}, 2 \mathrm{H}), 1.02(\mathrm{t}, 3 \mathrm{H}, J=7.2 \mathrm{~Hz})$; HRMS (ESI), $m / z: 422.1472[\mathrm{M}+\mathrm{H}]^{+}$.

\subsubsection{General Procedure for the Synthesis of Compounds $\mathbf{7 j}, \mathbf{7 k}, 7 \mathbf{l}$ and $\mathbf{1 4 c}$}

Sodium hydride ( $3 \mathrm{mmol}$ ) was added slowly to a cold solution of compound $7 \mathbf{g}, \mathbf{7 h}, \mathbf{7 i}$ or $\mathbf{1 4 b}(1 \mathrm{mmol})$ in THF $(1.5 \mathrm{~mL})$ under a nitrogen atmosphere. The ice bath was then removed after $30 \mathrm{~min}$, and the mixture was stirred at room temperature for $5 \mathrm{~h}$. After the reaction was completed, the mixture was diluted with cold water, and the resulting precipitate was filtered, washed with cold water and cold ether, then dried to afford the target compounds without further purification. 
4-Chloro-2-methoxy-N-(1-(4-(2-oxoimidazolidin-1-yl)benzyl)piperidin-4-yl)benzamide (7j). Yield 55.2\%; White solid; ${ }^{1} \mathrm{H}-\mathrm{NMR}\left(\mathrm{CDCl}_{3}\right): \delta 8.15(\mathrm{~d}, 1 \mathrm{H}, J=2.4 \mathrm{~Hz}), 7.77(\mathrm{~d}, 1 \mathrm{H}, J=7.2 \mathrm{~Hz}), 7.48(\mathrm{~d}$, $1 \mathrm{H}, J=8.4 \mathrm{~Hz}), 7.37(\mathrm{dd}, 1 \mathrm{H}, J=8.8 \mathrm{~Hz}, J=2.8 \mathrm{~Hz}), 7.30(\mathrm{~d}, 2 \mathrm{H}, J=8.4 \mathrm{~Hz}), 6.90(\mathrm{~d}, 2 \mathrm{H}$, $J=8.8 \mathrm{~Hz}), 4.03(\mathrm{~m}, 1 \mathrm{H}), 3.96-3.92(\mathrm{~m}, 4 \mathrm{H}), 3.58(\mathrm{t}, 2 \mathrm{H}, J=8.0 \mathrm{~Hz}), 3.50(\mathrm{~s}, 2 \mathrm{H}), 2.79(\mathrm{~m}, 2 \mathrm{H}), 2.22$ (t, $2 \mathrm{H}, J=10.4 \mathrm{~Hz}), 2.01(\mathrm{~d}, 2 \mathrm{H}, J=10.4 \mathrm{~Hz}), 1.58$ (q, 2H, $J=10.4 \mathrm{~Hz})$; HRMS (ESI), $m / z: 443.1772$ $[\mathrm{M}+\mathrm{H}]^{+}$.

3-Fluoro-N-(1-(4-(2-oxoimidazolidin-1-yl)benzyl)piperidin-4-yl)-4-(trifluoromethyl)benzamide (7k). Yield 66.4\%; White solid; ${ }^{1} \mathrm{H}-\mathrm{NMR}\left(\mathrm{CDCl}_{3}\right): \delta 8.52(\mathrm{~d}, 1 \mathrm{H}, J=2.4 \mathrm{~Hz}), 8.17(\mathrm{~s}, 1 \mathrm{H}), 8.14(\mathrm{~d}, 1 \mathrm{H}$, $J=8.0 \mathrm{~Hz}), 7.89(\mathrm{~d}, 1 \mathrm{H}, J=7.6 \mathrm{~Hz}), 7.71(\mathrm{t}, 1 \mathrm{H}, J=7.6 \mathrm{~Hz}), 7.10(\mathrm{~d}, 2 \mathrm{H}, J=8.4 \mathrm{~Hz}), 6.98(\mathrm{~d}, 2 \mathrm{H}$, $J=8.4 \mathrm{~Hz}), 3.80-3.76(\mathrm{~m}, 1 \mathrm{H}), 3.36(\mathrm{~s}, 2 \mathrm{H}), 3.58(\mathrm{t}, 2 \mathrm{H}, J=8.0 \mathrm{~Hz}), 2.79(\mathrm{~m}, 2 \mathrm{H}), 2.84(\mathrm{~d}, 2 \mathrm{H}$, $J=11.6 \mathrm{~Hz}), 1.99(\mathrm{t}, 2 \mathrm{H}, J=10.8 \mathrm{~Hz}), 1.87-1.77(\mathrm{~m}, 2 \mathrm{H}), 1.61-1.53$ (m, 2H); HRMS (ESI), $m / z$ : $465.1835[\mathrm{M}+\mathrm{H}]^{+}$.

N-(1-(4-(2-Oxoimidazolidin-1-yl)benzyl)piperidin-4-yl)-3-(trifluoromethyl)benzamide (7l). Yield 47.9\%; White solid; ${ }^{1} \mathrm{H}-\mathrm{NMR}$ (DMSO- $\left.d_{6}\right): \delta 8.01(\mathrm{~s}, 1 \mathrm{H}), 7.93(\mathrm{~d}, 1 \mathrm{H}, J=7.6 \mathrm{~Hz}), 7.75(\mathrm{~d}, 1 \mathrm{H}$, $J=7.6 \mathrm{~Hz}), 7.57(\mathrm{t}, 1 \mathrm{H}, J=7.6 \mathrm{~Hz}), 7.50$ (d, 2H, $J=8.4 \mathrm{~Hz}), 7.30(\mathrm{~d}, 2 \mathrm{H}, J=8.4 \mathrm{~Hz}), 6.10(\mathrm{~d}, 1 \mathrm{H}$, $J=7.2 \mathrm{~Hz}), 4.04-4.02(\mathrm{~m}, 1 \mathrm{H}), 3.95(\mathrm{t}, 2 \mathrm{H}, J=8.0 \mathrm{~Hz}), 3.58(\mathrm{t}, 2 \mathrm{H}, J=8.0 \mathrm{~Hz}), 2.90(\mathrm{~m}, 2 \mathrm{H}), 2.20$ $(\mathrm{m}, 2 \mathrm{H}), 2.02(\mathrm{~m}, 2 \mathrm{H}), 1.61(\mathrm{~m}, 2 \mathrm{H})$; HRMS (ESI), $m / z: 447.1930[\mathrm{M}+\mathrm{H}]^{+}$.

1-(4-((1-(3-Fluoro-4-(trifluoromethyl)benzoyl)piperidin-4-yl)oxy)phenyl)imidazolidin-2-one

(14c). Yield 35.2\%; White solid; ${ }^{1} \mathrm{H}-\mathrm{NMR}\left(\mathrm{CDCl}_{3}\right): \delta 7.67(\mathrm{t}, 1 \mathrm{H}, J=7.6 \mathrm{~Hz}), 7.54(\mathrm{~d}, 2 \mathrm{H}, J=9.2 \mathrm{~Hz}), 6.91$ $(\mathrm{d}, 2 \mathrm{H}, J=9.2 \mathrm{~Hz}), 4.69(\mathrm{~m}, 1 \mathrm{H}), 4.55(\mathrm{~m}, 2 \mathrm{H}), 3.93-3.87(\mathrm{~m}, 4 \mathrm{H}), 3.57$ (t, 2H, $J=8.0 \mathrm{~Hz}), 1.97-1.84$ (m, 4H); HRMS (ESI), $m / z: 452.1519[\mathrm{M}+\mathrm{H}]^{+}$.

\subsubsection{General Procedure for the Synthesis of 9}

A solution of tert-butyl 4-hydroxypiperidine-1-carboxylate $(5.0 \mathrm{mmol})$ in dry pyridine $(15 \mathrm{~mL})$ was stirred at $0{ }^{\circ} \mathrm{C}$ for $10 \mathrm{~min}$, and a solution of $\mathrm{TsCl}(7.5 \mathrm{mmol})$ in dry pyridine $(20 \mathrm{~mL})$ was added slowly. The mixture was stirred at room temperature for $6 \mathrm{~h}$. After the reaction was completed, the mixture was poured into ice water. And then the precipitate was collected by filtration, washed with water, and dried in vacuo to afford 9 as a white solid.

3.2.8. General Procedure for the Synthesis of 4-(4-Nitrophenoxy)piperidine (11)

A mixture of 9 (5.0 mmol), 4-nitrophenol 10 (5.5 mmol), and $\mathrm{K}_{2} \mathrm{CO}_{3}(10.0 \mathrm{mmol})$ in $\mathrm{DMF}(15 \mathrm{~mL})$ was heated to $100{ }^{\circ} \mathrm{C}$ for $10 \mathrm{~h}$. After the reaction was completed, the $\mathrm{K}_{2} \mathrm{CO}_{3}$ was removed by filtration. The filtrate was poured into ice water and extracted with $\mathrm{DCM}$, saturated $\mathrm{NaHCO}_{3}$, and brine, and the combined organic layer was dried with $\mathrm{MgSO}_{4}$. Finally, the solvent was removed under reduced pressure to give the crude. A solution of the above crude solid $(1.0 \mathrm{mmol})$ in $1 \mathrm{~mL} \mathrm{TFA} / \mathrm{DCM}$ $(\mathrm{v} / \mathrm{v}=1 / 1)$ was stirred for $3 \mathrm{~h}$ at $0{ }^{\circ} \mathrm{C}$, then allowed to warm to room temperature. After the reaction was completed, the solvent was removed under reduced pressure. The residue was slowly made alkaline with $2 \mathrm{~N} \mathrm{NaOH}$, then the precipitate formed was collected by filtration and washed with water to afford the crude product 11 without further purification. Yield 89.5\%; White solid; ${ }^{1} \mathrm{H}-\mathrm{NMR}$ (DMSO- 
$\left.d_{6}\right): \delta 8.20(\mathrm{~d}, 2 \mathrm{H}, J=9.2 \mathrm{~Hz}), 6.96(\mathrm{~d}, 2 \mathrm{H}, J=8.0 \mathrm{~Hz}), 4.08(\mathrm{~m}, 1 \mathrm{H}), 3.73-3.67(\mathrm{~m}, 2 \mathrm{H}), 3.41-3.35$ $(\mathrm{m}, 2 \mathrm{H}), 1.99-1.94(\mathrm{~m}, 2 \mathrm{H}), 1.80-1.77(\mathrm{~m}, 2 \mathrm{H})$; MS (ESI), $m / z: 323.15[\mathrm{M}+\mathrm{H}]^{+}$.

\subsubsection{General Procedure for the Synthesis of $\mathbf{1 6}$}

The corresponding amine $(2.0 \mathrm{mmol})$ in DCM was treated with mercury (II) chloride $(2.2 \mathrm{mmol})$, $N, N^{\prime}$-di(tert-butoxycarbonyl)thiourea $(2.0 \mathrm{mmol})$ and TEA $(6.3 \mathrm{mmol})$ at $0{ }^{\circ} \mathrm{C}$. The ice bath was removed after $1 \mathrm{~h}$, and the resulting mixture was at room temperature overnight. Then, the reaction mixture was filtered through a pad of Celite to get rid of the mercury sulfide formed. The filter cake was rinsed with DCM. The organic phase was concentrated under vacuum to give a residue that was purified by silica gel column chromatography to afford the title compound.

\subsubsection{General Procedure for the Synthesis of $\mathbf{1 7}$}

Each of the corresponding Boc-protected precursors $(0.5 \mathrm{mmol})$ was treated with TFA/ DCM $(15 \mathrm{~mL}$, $\mathrm{v} / \mathrm{v}=1 / 1$ ) acid in DCM for $3 \mathrm{~h}$. After the reaction was completed, the solvent was removed under reduced pressure. The residue was slowly basified with saturated $\mathrm{NaHCO}_{3}$, extracted with EtOAc. The organic phase was washed with water and brine, then dried over anhydrous $\mathrm{Na}_{2} \mathrm{SO}_{4}$ and concentrated under vacuum to give a residue that was purified by silica gel column chromatography to afford the title compound.

N-(1-(4-Guanidinobenzyl)piperidin-4-yl)-3-(trifluoromethyl)benzamide (17a). Yield 30.7\%; Yellow solid; ${ }^{1} \mathrm{H}-\mathrm{NMR}\left(\mathrm{DMSO}_{6}\right): \delta 8.64(\mathrm{~d}, 1 \mathrm{H}, J=7.2 \mathrm{~Hz}), 8.18(\mathrm{~d}, 2 \mathrm{H}, J=8.0 \mathrm{~Hz}), 7.90(\mathrm{~d}, 2 \mathrm{H}$, $J=8.0 \mathrm{~Hz}), 7.71(\mathrm{t}, 2 \mathrm{H}, J=8.0 \mathrm{~Hz}), 7.59(\mathrm{bs}, 3 \mathrm{H}), 7.36(\mathrm{~d}, 2 \mathrm{H}, J=7.6 \mathrm{~Hz}), 7.18$ (d, 2H, $J=7.6 \mathrm{~Hz})$, $3.48(\mathrm{~s}, 2 \mathrm{H}), 2.85(\mathrm{~d}, 2 \mathrm{H}, J=10.8 \mathrm{~Hz}), 2.09-1.99(\mathrm{~m}, 2 \mathrm{H}), 1.79(\mathrm{~m}, 2 \mathrm{H}), 1.66-1.57$ (m, 2H); HRMS (ESI), $m / z: 420.1933[\mathrm{M}+\mathrm{H}]^{+}$.

3-Fluoro-N-(1-(4-guanidinobenzyl)piperidin-4-yl)-4-(trifluoromethyl)benzamide (17b). Yield 45.2\%; White solid; ${ }^{1} \mathrm{H}-\mathrm{NMR}\left(\mathrm{DMSO}_{\mathrm{d}}\right)$ : $\delta 8.55(\mathrm{~d}, 1 \mathrm{H}, J=7.6 \mathrm{~Hz}), 7.93-7.85(\mathrm{~m}, 3 \mathrm{H}), 7.11(\mathrm{~d}, 2 \mathrm{H}$, $J=8.0 \mathrm{~Hz}), 6.77(\mathrm{~d}, 2 \mathrm{H}, J=8.0 \mathrm{~Hz}), 3.77(\mathrm{~m}, 1 \mathrm{H}), 3.37(\mathrm{~s}, 2 \mathrm{H}), 2.84(\mathrm{~d}, 2 \mathrm{H}, J=11.6 \mathrm{~Hz}), 1.99(\mathrm{t}, 2 \mathrm{H}$, $J=11.2 \mathrm{~Hz}), 1.80-1.78(\mathrm{~m}, 2 \mathrm{H}), 1.60-1.54(\mathrm{~m}, 2 \mathrm{H})$; HRMS (ESI), $m / z: 438.1839[\mathrm{M}+\mathrm{H}]^{+}$.

4-Chloro-N-(1-(4-guanidinobenzyl)piperidin-4-yl)-2-methoxybenzamide (17c). Yield 35.2\%; White solid; ${ }^{1} \mathrm{H}-\mathrm{NMR}\left(\mathrm{DMSO}_{\mathrm{d}}\right): \delta 8.08(\mathrm{~d}, 1 \mathrm{H}, J=7.2 \mathrm{~Hz}), 7.59(\mathrm{~d}, 1 \mathrm{H}, J=2.4 \mathrm{~Hz}), 7.49$ (dd, 1H, $J=8.8 \mathrm{~Hz}, J=2.4 \mathrm{~Hz}), 7.23(\mathrm{t}, 2 \mathrm{H}, J=7.6 \mathrm{~Hz}), 7.15(\mathrm{~d}, 1 \mathrm{H}, J=8.8 \mathrm{~Hz}), 6.98(\mathrm{~d}, 2 \mathrm{H}, J=7.6 \mathrm{~Hz})$, $3.86(\mathrm{~s}, 3 \mathrm{H}), 3.77(\mathrm{~m}, 1 \mathrm{H}), 3.41(\mathrm{~s}, 2 \mathrm{H}), 2.75(\mathrm{~d}, 2 \mathrm{H}, J=10.0 \mathrm{~Hz}), 2.06(\mathrm{t}, 2 \mathrm{H}, J=10.0 \mathrm{~Hz}), 1.80-1.77$ (m, 2H), 1.04 (q, 2H, $J=10.0 \mathrm{~Hz}$ ); HRMS (ESI), $m / z: 416.1775[\mathrm{M}+\mathrm{H}]^{+}$.

2,2-Difluoro-N-(1-(4-guanidinobenzyl)piperidin-4-yl)benzo[d][1,3]dioxole-4-carboxamide

(17d). Yield 25.9\%; Yellow solid; ${ }^{1} \mathrm{H}-\mathrm{NMR}\left(\mathrm{CDCl}_{3}\right): \delta$ 7.75-7.72 (m, $\left.1 \mathrm{H}\right), 7.41(\mathrm{~d}, 2 \mathrm{H}, J=7.6 \mathrm{~Hz}), 7.20-7.15$ $(\mathrm{m}, 4 \mathrm{H}), 6.55(\mathrm{~d}, 2 \mathrm{H}, J=7.6 \mathrm{~Hz}), 4.04(\mathrm{~m}, 1 \mathrm{H}), 3.56(\mathrm{~s}, 2 \mathrm{H}), 2.86(\mathrm{~d}, 2 \mathrm{H}, J=10.4 \mathrm{~Hz}), 2.30-2.25(\mathrm{~m}$, 2H), 1.66 (q, 2H, $J=10.0 \mathrm{~Hz}), 1.60-1.54$ (m, 2H); HRMS (ESI), $m / z: 432.1769[\mathrm{M}+\mathrm{H}]^{+}$. 
N-(1-(4-Guanidinobenzyl)piperidin-4-yl)-3-(1,1,2,2-tetrafluoroethoxy)benzamide (17e). Yield 25.0\%; Yellow solid; ${ }^{1} \mathrm{H}-\mathrm{NMR}\left(\mathrm{DMSO}_{\mathrm{d}}\right)$ ): $\delta 7.79(\mathrm{~d}, 1 \mathrm{H}, J=6.8 \mathrm{~Hz}), 7.70(\mathrm{~s}, 1 \mathrm{H}), 7.53-7.43(\mathrm{~m}, 4 \mathrm{H}), 7.26$ $(\mathrm{d}, 2 \mathrm{H}, J=6.4 \mathrm{~Hz}), 6.48-6.22(\mathrm{~m}, 1 \mathrm{H}), 3.89(\mathrm{~m}, 1 \mathrm{H}), 3.63(\mathrm{~s}, 2 \mathrm{H}), 3.00(\mathrm{~d}, 2 \mathrm{H}, J=9.2 \mathrm{~Hz}), 2.22(\mathrm{t}, 2 \mathrm{H}$, $J=10.0 \mathrm{~Hz}), 1.96$ (d, 2H, $J=10.8 \mathrm{~Hz}), 1.73-1.70$ (m, 2H); MS (ESI), $m / z: 468.1944[\mathrm{M}+\mathrm{H}]^{+}$.

4-(Difluoromethoxy)-N-(1-(4-guanidinobenzyl)piperidin-4-yl)benzamide (17f). Yield 22.4\%; White solid; ${ }^{1} \mathrm{H}-\mathrm{NMR}\left(\mathrm{CD}_{3} \mathrm{OD}\right): \delta 7.76(\mathrm{~d}, 2 \mathrm{H}, J=8.4 \mathrm{~Hz}), 7.37(\mathrm{~d}, 2 \mathrm{H}, J=7.6 \mathrm{~Hz}), 7.16(\mathrm{~d}, 2 \mathrm{H}$, $J=8.4 \mathrm{~Hz}), 7.10(\mathrm{~d}, 2 \mathrm{H}, J=8.4 \mathrm{~Hz}), 7.02-6.65(\mathrm{~m}, 1 \mathrm{H}), 3.84-3.77(\mathrm{~m}, 1 \mathrm{H}), 3.53(\mathrm{~s}, 2 \mathrm{H}), 2.90(\mathrm{~d}, 2 \mathrm{H}$, $J=11.6 \mathrm{~Hz}), 2.15(\mathrm{t}, 2 \mathrm{H}, J=11.6 \mathrm{~Hz}), 1.85$ (d, 2H, $J=9.6 \mathrm{~Hz}), 1.64-1.56$ (m, 2H); HRMS (ESI), $m / z$ : $418.1976[\mathrm{M}+\mathrm{H}]^{+}$.

N-(1-(4-Guanidinobenzyl)piperidin-4-yl)nicotinamide (17g). Yield 20.7\%; White solid; ${ }^{1} \mathrm{H}-\mathrm{NMR}$ $\left(\mathrm{CDCl}_{3}\right): \delta 8.54(\mathrm{~d}, 1 \mathrm{H}, J=4.4 \mathrm{~Hz}), 8.15(\mathrm{~d}, 1 \mathrm{H}, J=7.6 \mathrm{~Hz}), 8.01(\mathrm{~d}, 1 \mathrm{H}, J=8.4 \mathrm{~Hz}), 7.84(\mathrm{td}, 1 \mathrm{H}$, $J=7.6 \mathrm{~Hz}, J=1.6 \mathrm{~Hz}), 7.44-7.41(\mathrm{~m}, 1 \mathrm{H}), 7.38(\mathrm{~d}, 2 \mathrm{H}, J=8.4 \mathrm{~Hz}), 7.15(\mathrm{~d}, 2 \mathrm{H}, J=8.0 \mathrm{~Hz})$, 3.98-3.96 (m, 1H), $3.50(\mathrm{~s}, 2 \mathrm{H}), 2.82(\mathrm{~d}, 2 \mathrm{H}, J=11.6 \mathrm{~Hz}), 2.19(\mathrm{t}, 2 \mathrm{H}, J=10.8 \mathrm{~Hz}), 1.99$ (d, 2H, $J=10.4 \mathrm{~Hz}), 1.68-1.59(\mathrm{~m}, 2 \mathrm{H})$; HRMS (ESI), $m / z: 353.2012[\mathrm{M}+\mathrm{H}]^{+}$.

$\mathrm{N}$-(1-(4-((4,5-Dihydro-1H-imidazol-2-yl)amino)benzyl)piperidin-4-yl)-3-(trifluoromethyl)benzamide (17h). Yield 33.2\%; White solid; ${ }^{1} \mathrm{H}-\mathrm{NMR}\left(\mathrm{CDCl}_{3}\right): \delta 8.01(\mathrm{~s}, 1 \mathrm{H}), 7.92(\mathrm{~d}, 1 \mathrm{H}, J=7.6 \mathrm{~Hz}), 7.75(\mathrm{~d}$, $1 \mathrm{H}, J=7.6 \mathrm{~Hz}), 7.56(\mathrm{t}, 1 \mathrm{H}, J=7.6 \mathrm{~Hz}), 7.20(\mathrm{~d}, 2 \mathrm{H}, J=8.0 \mathrm{~Hz}), 6.96(\mathrm{~d}, 2 \mathrm{H}, J=8.0 \mathrm{~Hz}), 6.08(\mathrm{~d}$, $1 \mathrm{H}, J=7.6 \mathrm{~Hz}), 4.02-4.00(\mathrm{~m}, 1 \mathrm{H}), 3.54(\mathrm{~m}, 4 \mathrm{H}), 3.46(\mathrm{~s}, 2 \mathrm{H}), 2.87(\mathrm{~d}, 2 \mathrm{H}, J=11.6 \mathrm{~Hz}), 2.16(\mathrm{t}, 2 \mathrm{H}$, $J=11.2 \mathrm{~Hz}), 2.02(\mathrm{~d}, 2 \mathrm{H}, J=11.2 \mathrm{~Hz}), 1.63-1.54(\mathrm{~m}, 2 \mathrm{H})$; HRMS (ESI), $m / z: 674.1947[\mathrm{M}+\mathrm{H}]^{+}$.

N-(1-(4-((4,5-Dihydro-1H-imidazol-2-yl)amino)benzyl)piperidin-4-yl)-3-fluoro-4-(trifluoromethyl)benzamide (17i). Yield 38.1\%; White solid; ${ }^{1} \mathrm{H}-\mathrm{NMR}\left(\mathrm{CDCl}_{3}\right): \delta 7.67-7.59(\mathrm{~m}, 3 \mathrm{H}), 7.20(\mathrm{~d}, 2 \mathrm{H}$, $J=8.0 \mathrm{~Hz}), 6.95(\mathrm{~d}, 1 \mathrm{H}, J=8.0 \mathrm{~Hz}), 6.19$ (d, 1H, $J=7.6 \mathrm{~Hz}), 3.99(\mathrm{~m}, 1 \mathrm{H}), 3.45(\mathrm{~s}, 2 \mathrm{H}), 2.18-2.12(\mathrm{~m}$, 2H), 2.01-1.99 (m, 2H), 1.62-1.54 (m, 2H); HRMS (ESI), m/z: $692.1853[\mathrm{M}+\mathrm{H}]^{+}$.

\subsection{Biological Assay Methods}

\subsubsection{T3-L1 Adipocyte Differentiation}

Marine 3T3-L1 preadipocytes (American Type Culture Collection, Rockville, MD, USA) were plated and grown to two days post confluence in 96 well culture plates in DMEM containing $10 \%$ fetal bovine serum; Preadipocytes were induced to differentiate by replacing the medium with serum-containing DMEM containing $0.5 \mathrm{mM}$ methyl-3-isobutylxantine (IBMX), $0.25 \mathrm{mM}$ dexamethasone (DEX) and $1 \mathrm{mg} / \mathrm{mL}$ insulin. Two days later, the medium was again changed to serum-containing DMEM that contained insulin but no IBMX or DEX. Two days later, the medium was again changed to the original DMEM containing $10 \%$ fetal bovine serum in the absence of any differentiating reagents and was replaced every two days. Full differentiation is usually achieved by $8-12$ days. 


\subsubsection{Expression Levels of Leptin in 3T3-L1 Adipocytes}

The twelfth day after differentiation, the culture medium was replaced by DMEM supplemented with chemical series of 3 and $4(10 \mathrm{mM})$ and rosiglitazone (Sigma-Aldrich, St. Louis, MO, USA) $(10 \mathrm{mM})$. After $24 \mathrm{~h}$, the expression levels of leptin were measured by commercial kits (Linco Research, St. Charles, MO, USA).

\subsubsection{Animal Model and Treatment of Diet-Induced Obesity.}

C57BL/6J mice were obtained from Western China Experimental Animal Center and housed individually in a room maintained at $25{ }^{\circ} \mathrm{C}$ on a light/dark schedule. For DIO mice, 3-week-old male C57BL/6J mice were fed a high fat diet (HFD, Research Diets, Nanjing, china) ad libitum for 8 weeks. Then these animals were randomly assigned to four groups consisting of five mice each. The mice received a normal diet with $18.94 \%$ of energy derived from fat, $31.67 \%$ from protein, and $49.39 \%$ from carbohydrates and received a high fat diet with $60.0 \%$ of calories from fat, $20.0 \%$ from protein, and $20.0 \%$ from carbohydrates. HFD + Met $(150 \mathrm{mg} / \mathrm{kg} /$ day $)$ and HFD + 7i (50 mg/kg/day) in PEG400 or vehicle were orally administered per day for five weeks. Body weight and food intake were measured per day. And serum levels of biomarkers were analyzed after all animals were sacrificed. The percentages were calculated using the formula $\left[\left(\mathrm{V}_{\mathrm{HFD}}-\mathrm{V}_{\text {treatment }}\right) / \mathrm{V}_{\mathrm{HFD}}\right] \times 100$.

\subsubsection{Assay for Serum Biochemical Markers}

Serum ALT and AST levels were measured by an automated enzymeassay using commercial kits and Roche automated analyzers (RocheDiagnostics GmbH, Manheim, Germany). Serum levels of TG, LDL cholesterol, HDL-cholesterol, and plasma insulin were determined by radioimmunoassay using commercially available kits (Linco Research).

\subsubsection{Histopathological Examination}

Liver samples were fixed in $4 \%$ buffered formalin and embedded in Tissue-Tek OCT compound (Sakura Finetek USA, Torrance, CA, USA) and paraffin for histological analysis. Formalin-fixed and paraffin embedded section $(5 \mathrm{~mm})$ was processed routinely for H\&E staining. The OCT-embedded samples were serially sectioned at $4 \mathrm{~mm}$. For the evaluation of fat deposition, the frozen liver sections was stained with Oil red O.

\section{Conclusions}

In this study, twenty eight novel (thio)urea- and guanidine-based derivatives have been synthesized by an easy and practicable synthetic method. Subsequently, a credible screening method was adopted to evaluate their bioactivity and $\mathbf{7 i}$ was proved to be a potential agent against diet-induced hepatic steatosis. The pharmacological evaluation was started with the leptin expression on 3T3-L1 adipocytes, and among the tested compounds, $7 \mathbf{i}$ displayed potent capacity in decreasing leptin levels at $10 \mu \mathrm{M}$. The weight of body and liver of high-fat diet induced mice were effectively reduced after oral administration of $7 \mathbf{i}$ at a dose of $50 \mathrm{mg} / \mathrm{kg}$ /day for five weeks. At the same time, 7i modulated 
serum parameters of leptin, adiponectin, TG, TC, LDL-c and HDL-c to appropriate ranges. Consistent with the reduction of liver weight, further H\&E and Oil Red O staining confirmed 7i reduced fat deposition in the liver tissue and restricted the size of adipocytes against fatty liver disease. In summary, these compelling results suggested that 7i improved the progression of obesity-related hepatic dysfunctions and protected the liver tissue in diet-induced obese mice. Research on the detailed pharmacokinetics and action of mechanism of $\mathbf{7 i}$ are in progress.

\section{Supplementary Materials}

Supplementary materials can be accessed at: http://www.mdpi.com/1420-3049/19/5/6163/s1.

\section{Acknowledgments}

The authors greatly appreciate the financial support from National Key Programs of China during the 12th Five-Year Plan Period (Grant 2012ZX09103101-033)

\section{Author Contributions}

L.X, P.H and C.L designed research; L.X, and P.H performed research and analyzed the data; M.L, R.Y, C.J, and W.G helped analyzed the data. L.X wrote the paper. All authors read and approved the final manuscript.

\section{Conflicts of Interest}

The authors declare no conflict of interest.

\section{References}

1. Bray, G.A. Obesity: The disease. J. Med. Chem. 2006, 49, 4001-4007.

2. Kelly, T.; Yang, W.; Chen, C.-S.; Reynolds, K.; He, J. Global burden of obesity in 2005 and projections to 2030. Int. J. Obesity. 2008, 32, 1431-1437.

3. O'Brien, P.E.; Dixon, J.B. The extent of the problem of obesity. Am. J. Surg. 2002, 184, S4-S8.

4. Pi-Sunyer, F.X. Medical hazards of obesity. Ann. Intern. Med. 1993, 119, 655-660.

5. Feneberg, A.; Malfertheiner, P. Epidemic trends of obesity with impact on metabolism and digestive diseases. Digest. Dis. 2012, 30, 143-147.

6. Schindhelm, R.K.; Diamant, M.; Dekker, J.M.; Tushuizen, M.E.; Teerlink, T.; Heine, R.J. Alanine aminotransferase as a marker of non-alcoholic fatty liver disease in relation to type 2 diabetes mellitus and cardiovascular disease. Diabetes. Metab. Res. Rev. 2006, 22, 437-443.

7. Bacon, B.R.; Farahvash, M.J.; Janney, C.G.; Neuschwander-Tetri, B.A. Nonalcoholic steatohepatitis: An expanded clinical entity. Gastroenterology 1994, 107, 1103-1109.

8. Henao-Mejia, J.; Elinav, E.; Jin, C.; Hao, L.; Mehal, W.Z.; Strowig, T.; Thaiss, C.A.; Kau, A.L.; Eisenbarth, S.C.; Jurczak, M.J.; et al. Inflammasome-mediated dysbiosis regulates progression of NAFLD and obesity. Nature 2012, 482, 179-186.

9. Angulo, P. Nonalcoholic fatty liver disease. N. Engl. J. Med. 2002, 346, 1221-1231. 
10. Browning, J.D.; Horton, J.D. Molecular mediators of hepatic steatosis and liver injury. J. Clin. Invest. 2004, 114, 147-152.

11. Jéquier, E. Leptin signaling, adiposity, and energy balance. Ann. N. Y. Acad. Sci. 2002, 967, 379-388.

12. Børbaek, C.; Kahn, B.B. Leptin signaling in the central nervous system and the periphery. Prog. Horm. Res. 2004, 59, 305-331.

13. Dellas, C.; Lankeit, M.; Reiner, C.; Schäfer, K.; Hasenfuß, G.; Konstantinides, S. BMI-independent inverse relationship of plasma leptin levels with outcome in patients with acute pulmonary embolism. Int. J. Obes. (Lond.) 2013, 37, 204-210.

14. Considine, R.V.; Sinha, M.K.; Heiman, M.L.; Kriauciunas, A.I.; Stephens, T.W.; Nyce, M.R.; Ohannesian, J.P.; Marco, C.C.; Mckee, L.J.; Bauer, T.L.; et al. Serum immunoreactive-leptin concentrations in normal-weight and obese humans. N. Engl. J. Med. 1996, 334, 292-295.

15. Roberts, E.A. Pediatric nonalcoholic fatty liver disease (NAFLD): A "growing" problem? J. Hepatol. 2007, 46, 1133-1142.

16. Pérez, C.; Fernández-Galaz, C.; Fernández-Agulló, T.; Arribas, C.; Andrés, A.; Ros, M.; Carrascosa, J.M. Leptin impairs insulin signaling in rat adipocytes. Diabetes 2004, 53, 347-353.

17. Cohen, B.; Novick, D.; Rubinstein, M. Modulation of insulin activities by leptin. Science 1996, 274, 1185-1188.

18. Muller, G.; Ertl, J.; Gerl, M.; Preibish, G. Leptin impairs metabolic actions of insulin in isolated rat adipocytes. J. Biol. Chem. 1997, 272, 10585-10593.

19. Valerio, N.; Melania, M.; Paolo, C.; Vincenzo, D.; Rita, D.; Fiorella, P.; Roberto, C.; Donatella, G.; Matilde, M. Leptin, free leptin index, insulin resistance and liver fibrosis in children with non-alcoholic fatty liver disease. Eur. J. Endocrinol. 2006, 155, 735-743.

20. Lewis, G.F.; Carpentier, A.; Adeli, K.; Giacca, A. Disordered fat storage and mobilization in the pathogenesis of insulin resistance and type 2 diabetes. Endocr. Rev. 2002, 23, 201-229.

21. Leclercq, I.A.; Farrell, G.C.; Schriemer, R.; Robertson, G.R. Leptin is essential for the hepatic fibrogenic response to chronic liver injury. J. Hepatol. 2002, 37, 206-213.

22. Imajo, K.; Fujita, K.; Yoneda, M.; Nozaki, Y.; Ogawa, Y.; Shinohara, Y.; Kato, S.; Mawatari, H.; Shibata, W.; Kitani, H.; et al. Hyperresponsivity to low-dose endotoxin during progression to nonalcoholic steatohepatitis is regulated by leptin-mediated signaling. Cell. MeTable 2012, 16, 44-54.

23. Patel, K.; Muir, A., McHutchison, J.G.; Patton, H.M. A link between leptin and steatosis in chronic hepatitis C? Time to weigh up the fats. Am. J. Gastroenterol. 2003, 98, 952-955.

24. Freemark, M.; Bursey, D. The effects of metformin on body mass index and glucose tolerance in obese adolescents with fasting hyperinsulinemia and a family history of type 2 diabetes. Pediatrics 2001, 107, E55.

25. Duseja, A.; Das, A.; Dhiman, R.K.; Chawla, Y.K.; Thumburu, K.T.; Bhadada, S.; Bhansali, A. Metformin is effective in achieving biochemical response in patients with nonalcoholic fatty liver disease (NAFLD) not responding to lifestyle interventions. Ann. Hepatol. 2007, 6, 222-226.

26. Stein, L.L.; Dong, M.H.; Loomba, R. Insulin Sensitizers in Nonalcoholic Fatty Liver Disease and Steatohepatitis: Current Status. Adv. Ther. 2009, 26, 893-907.

27. Plosker, GL.; Faulds, D. Troglitazone: A review of its use in themanagement of type 2 diabetes mellitus. Drugs 1999, 57, 409-438. 
28. Pereira, C.V.; Moreira, A.C.; Pereira, S.P.; Machado, N.G.; Carvalho, F.S.; Sardao, V.A.; Oliveira, P.J. Investigating Drug-induced Mitochondrial Toxicity: A Biosensor to Increase Drug Safety? Curr. Drug Saf. 2009, 4, 34-54.

29. Venier, O.; Pascal, C.; Braun, A.; Namane, C.; Mougenot, P.; Crespin, O.; Pacquet, F.; Mougenot, C.; Monseau, C.; Onofri, B.; et al. Pyrrolidine-pyrazole ureas as potent and selective inhibitors of 11ß-hydroxysteroid-dehydrogenase type 1. Bioorg. Med. Chem. Lett. 2011, 21, 2244-2251.

30. Sophie, P.; Peter, R.M.; Steve, S.; Veronique, G. Fluorine in medicinal chemistry. Chem. Soc. Rev. 2008, 37, 320-330.

31. Hoffler, U.; Hobbie, K.; Wilson, R.; Bai, R.; Rahman, A.; Malarkey, D.; Travlos, G.; Ghanayem, B.I. Diet-induced obesity is associated with hyperleptinemia, hyperinsulinemia, hepatic steatosis, and glomerulopathy in C57B1/6J mice. Endocrine 2009, 36, 311-325.

32. Kang, H.S.; Okamoto, K.; Takeda, Y.; Beak, J.Y.; Gerrish, K.; Bortner, C.D.; DeGraff, L.M.; Wada, T.; Xie, W.; Jetten, A.M. Transcriptional profiling reveals a role for ROR $\alpha$ in regulating gene expression in obesity-associated inflammation and hepatic steatosis. Physiol. Genomics 2011, 43, 818-828.

33. Adachi, M.; Brenner, D.A. High molecular weight adiponectin inhibits proliferation of hepatic stellate cells via activation of adenosine monophosphate-activated protein kinase. Hepatology 2008, 47, 677-685.

34. Polyzos, S.A.; Kountouras, J.; Zavos, C.; Tsiaousi, E. The role of adiponectin in the pathogenesis and treatment of non-alcoholic fatty liver disease. Diabetes Obes. Metab. 2010, 12, 365-383.

35. Wang, Y.; Zhou, M.; Lam, K.S.; Xu, A. Protective roles of adiponectin in obesity-related fatty liver diseases: Mechanisms and therapeutic implications. Arq. Bras. Endocrinol. Metabol. 2009, 53, 201-212.

36. Hench, J.; Hench, I.B.; Pujol, C.; Ipsen, S.; Brodesser, S.; Mourier, A.; Tolnay, M.; Frank, S.; Trifunović, A. A tissue-specific approach to the analysis of metabolic changes in Caenorhabditis elegans. PLoS One 2011, 6, e28417.

37. Cook, H.C. Origins of Tinctorial methods in histology. J. Lin. Pathol. 1997, 50, 716-720.

Sample Availability: Samples of the compounds $7 \mathbf{a}-\mathbf{- 1}, \mathbf{8 a}-\mathbf{c}, \mathbf{1 4 a}-\mathbf{d}, \mathbf{1 7} \mathbf{a}-\mathbf{i}$ are available from the authors.

(C) 2014 by the authors; licensee MDPI, Basel, Switzerland. This article is an open access article distributed under the terms and conditions of the Creative Commons Attribution license (http://creativecommons.org/licenses/by/3.0/). 